ISSN: 2386-3919 - e-ISSN: 2386-3927

DOI: http://dx.doi.org/10.14201/et20163415792

\title{
PRÁCTICAS DE LECTURA DIGITAL DE ESTUDIANTES UNIVERSITARIOS
}

\section{Digital reading practices of university students}

\author{
Karen Shirley López GIL \\ Pontificia Universidad Javeriana, Cali, Colombia. \\ Correo-e:karens@javerianacali.edu.co
}

Recibido: 16-08-2015; Aceptado: 09-11-2015; Publicado: 30-05-2016

BIBLID [2386-3919 (2016) 34, 1; 57-92]

Ref. Bibl. KAREN SHIRLEY LÓPEZ GIL. Prácticas de lectura digital de estudiantes universitarios. Enseñanza \& Teaching, 34, 1-2016, 57-92.

RESUMEN: Se presentan los resultados de una investigación que buscaba analizar las prácticas de lectura digital de estudiantes universitarios y la manera como estas prácticas son orientadas por los docentes e instituciones de educación superior. El diseño de investigación fue mixto y el tipo de estudio descriptivo de corte transversal. Las técnicas de recolección de información fueron el cuestionario, el análisis documental y el grupo de discusión. Para el tratamiento de los datos se hizo un análisis estadístico con el IBM SPSS v.22 y análisis de contenido con Atlas.Ti 7.0 para los datos de naturaleza cualitativa. Se encontró que los estudiantes leen con frecuencia en pantallas, aunque muchas de sus prácticas tienen fines recreativos. Cuando leen con propósitos académicos, los estudiantes tienen problemas para evaluar la confiabilidad de la información que encuentran en la Red y consultan con mayor frecuencia fuentes secundarias. Una vez tienen los textos en pantalla, abordan de manera general la información y transitan por varios documentos a través de hipervínculos. Los límites entre las actividades de ocio y las académicas no están bien definidos, pues aparece con frecuencia la multitarea. Los estudiantes indican que son escasas las orientaciones que reciben por parte de los docentes o de la universidad. A partir de estos hallazgos se evidencia que los alumnos se enfrentan constantemente a la lectura digital, pero las prácticas que llevan a cabo no siempre les permiten alcanzar 
sus propósitos académicos, por lo que es necesario fortalecer los apoyos que se les ofrecen, principalmente desde las aulas de lengua.

Palabras clave: prácticas de lectura; soporte digital; estudiantes; universidad; enseñanza.

SUMMARY: This paper presents results of research on digital reading. The main objective of the research was to analyze the reading on screens practices of university students and how their practices are guided by professors and institutions of higher education. The research design was mixed and the type of study was descriptive of cross-sectional. The data collection techniques were questionnaire, document analysis and discussion group. IBM SPSS v.22 was used for statistical treatment of data and Atlas.Ti 7.0 was used for content analysis of qualitative information. The study showed that students usually read on screens, although many of their reading practices have recreational purposes. Students have troubles to find reliable information on the Internet when they have academic pursuits and frequently consult secondary sources. When texts are on screens, students generally scan information and surf from one document to another along hyperlinks. The boundaries between academic and leisure activities are not well defined; multitasking appears frequently. Students indicate there is a little guidance received from their professors or university. These findings show that students are constantly faced with digital reading, but practices do not always allow them to achieve their academic purposes, so it is necessary to strengthen the support offered to them, mainly from the classroom language.

Key words: reading practices; digital media; students; university; teaching.

\section{INTRODUCCIÓN}

La lectura es ampliamente reconocida como una herramienta fundamental en el acceso, construcción y comunicación de los conocimientos en las distintas disciplinas (Gee, 1990; Lea, 2004; Bazerman et al., 2005; Carlino, 2005). De allí que en las últimas décadas se haya dado un importante crecimiento en el número de investigaciones sobre este proceso en el contexto universitario (Carlino, 2013). El desarrollo de dispositivos tecnológicos y la conexión a Internet han reconfigurado los modos de leer y de acercarse a la cultura académica escrita (Cassany, 2013). Nos encontramos ante la circulación de nuevas y tradicionales maneras de organizar la información, coexisten los soportes impresos y digitales, distintas modalidades de representación del conocimiento, así como tipologías textuales y géneros discursivos híbridos. En palabras de Chartier (1996):

[...] La representación electrónica de los textos modifica totalmente su condición: sustituye la materialidad del libro con la inmaterialidad de textos sin lugar propio; opone a las relaciones de contigüidad, establecidas en el objeto impreso, la libre composición de fragmentos manipulables indefinidamente; a la aprehensión 
inmediata de la totalidad de la obra, hecha visible por el objeto que la contiene, hace que le suceda la navegación en el largo curso de archipiélagos textuales en ríos movientes. Estas mutaciones ordenan, inevitablemente, imperativamente, nuevas maneras de leer, nuevas relaciones con lo escrito, nuevas técnicas intelectuales (p. 44).

A pesar de estas reconfiguraciones, la enseñanza de la lectura en la universidad sigue enfatizando en las prácticas tradicionales impresas, desatendiendo el soporte digital o dando por sentado que la población juvenil, por ser la que tiene mayor preferencia por la Red (Morduchowicz, 2013), ya ha desarrollado las competencias necesarias para enfrentarse a este soporte. Los ingresantes a las universidades, tanto por su edad como por su comportamiento, suelen incluirse dentro de los grupos denominados "nativos digitales» (Prensky, 2001), "residentes digitales" (Kruse, 2010) o "prosumidores». Estas metáforas dan cuenta de sus competencias en el manejo de programas informáticos y de sus interacciones a través de las pantallas, en las que leen con frecuencia.

Sin embargo, diversos estudios han evidenciado que este acercamiento a lo digital no implica necesariamente el dominio de las prácticas letradas que se requieren en el contexto académico (OCDE, 2011; Cassany, 2013), entre otras razones, porque los modos de leer en la universidad difieren considerablemente de los modos de hacerlo en los otros niveles educativos y en los otros dominios en los que se usa el lenguaje escrito.

Al respecto, Carlino (2005) plantea que es necesario reinterpretar las deficiencias que se atribuyen a los alumnos universitarios, ya que los desafíos que presentan en la lectura no se deben a una carencia, sino que al ingresar a este contexto se ven enfrentados a unas formas de leer y a unas culturas escritas propias de las disciplinas.

Sumado a las características del medio impreso, en la Red los estudiantes encuentran gran cantidad de información que tiene procedencia, contextos e incluso lenguas distintas. Los estudiantes enfrentan textos con estructuras menos lineales y con acceso inmediato a otras fuentes. Así mismo, los jóvenes tienen más posibilidades de realizar actividades paralelas a la lectura (Cassany, 2013; Morduchowicz, 2013). A pesar de presentar elementos potenciadores, estas características también pueden implicar riesgos como la infoxicación, el naufragio y el consumismo acrítico.

Estos elementos hacen que sea importante explorar y analizar las formas de lectura digital de los jóvenes que ingresan a la educación superior, considerando, además, que esta población tiene mayor riesgo de deserción escolar y que, «aunque el dominio de la lengua escrita no constituye el único factor causante de la deserción en la universidad, sí es posible afirmar que es uno de los más relevantes en tanto que permea todas las áreas del conocimiento, se involucra en la enseñanza de las ciencias y es necesario en todos los campos de la vida individual y social» (Cisneros, Olave y Rojas, 2012: 50). Por tanto, es preciso indagar cuáles son las prácticas cotidianas de los estudiantes para poder acercarnos a la comprensión de 
qué hacen cuando leen en pantallas, por qué, para qué, cómo, en qué condiciones, qué dificultades presentan y, a partir de ello, plantear posibles orientaciones desde las aulas.

\section{BREVE FUNDAMENTACIÓN}

\subsection{Lectura digital}

Desde enfoques socioculturales, la lectura se concibe como un proceso interactivo, social y discursivo; como una práctica letrada que implica la puesta en marcha de habilidades de procesamiento de la información, así como la ubicación en una situación comunicativa específica (Cassany y Ayala, 2008; Cassany, 2013). En la lectura participa un sujeto -con conocimientos previos e intenciones-, un texto -con un propósito, estructura, género, soporte- y un contexto sociocultural que enmarca la práctica lectora. De esta manera, la lectura constituye una de las actividades de más alto nivel cognitivo y es una de las formas privilegiadas para el acceso a la información y la construcción del conocimiento.

El texto no se considera neutro, sino un artefacto social y político que evidencia de manera más o menos explícita las intencionalidades del autor. El lector, además de comprender e interpretar los contenidos, debe evaluarlos críticamente, asumir roles y construir una identidad, por lo que leer se convierte en un acto de ejercicio de poder (Cassany, 2009).

En el medio digital la lectura se transforma. Esto no implica únicamente un cambio de superficie, sino una verdadera reconfiguración de los modos en que se puede acceder y relacionarse con los textos (Chartier, 1996; Scolari, 2004). Al respecto, Cassany (2013) indica que la característica más relevante de la lectura digital es la posibilidad de conectarse a Internet, pues estar conectado a la Red facilita el acceso inmediato a cientos de interlocutores y textos, así como a recursos sofisticados tales como diccionarios, bases de datos, traductores, redes sociales, entre otros.

De igual forma, leer en Internet incluye procesos que no estaban fuertemente marcados en la lectura en papel, entre ellos la búsqueda y selección de información (Coscarelli, 2009). En las bibliotecas, los textos han pasado por filtros. En la Red, los internautas se encuentran con infinidad de documentos que tienen niveles de confiabilidad distintos. Así, la lectura digital exige competencias en alfabetización informacional (navegar en la Red, seleccionar, comprender y usar de manera adecuada los textos), además de las competencias críticas que requiere la lectura en cualquier soporte (Cassany, 2013; Galindo, 2014).

\subsection{Características de los textos digitales}

Los textos que circulan en la Red no son homogéneos. Levratto (2014) hace una distinción entre textos digitalizados y digitales. Los primeros se refieren a aquellos que provienen de formatos impresos: textos lineales, cuya información 
se organiza predominantemente en modalidad escrita. Estos suelen ser escaneados o transcritos para ser visualizados en pantalla. Por otra parte, los textos digitales se han creado específicamente para la lectura electrónica. Su estructura suele ser no lineal, incluye vínculos y distintos modos de representación de la información (escrita, audiovisual, gráfica).

Los textos digitales suelen asumir las características del hipertexto. Este término, acuñado por Nelson (1965), describe un tipo de texto no secuencial, bifurcado, que permite que el lector elija los caminos a seguir. Al inicio esta palabra se relacionó con la posibilidad de conectar varios bloques de información a través de enlaces. Posteriormente, se fueron integrando a ella otras nociones como "multimedia", referida a la inclusión de distintos medios de presentación de información: visual, sonora, audiovisual y textual; e "hipermedia», que puede considerarse como la integración de la hipertextualidad y la multimedialidad (Cunliffe, 2000; Albarello, 2011).

Los hipertextos presentan una organización particular de la información, denominada estructura del hipertexto, que da cuenta de cómo se interconectan los nodos en la arquitectura en función de la estratificación y la complejidad de la conexión: lineales, jerárquicas y en redes (McEneaney, 2000). Además de su organización, los textos digitales se caracterizan por las relaciones explícitas de intertextualidad, esto quiere decir que aparecen vínculos que conectan inmediatamente con otros textos, lo que amplía la navegación. Para algunos autores esto puede ser una desventaja, pues si el lector no tiene las competencias necesarias puede "naufragar» entre tantos contenidos.

En la Red, y atendiendo a estas características posibilitadas por el hipertexto, aparecen entonces distintos géneros discursivos: las páginas web, los blogs, las redes sociales, las wikis, los correos electrónicos, entre otros, que no tienen una correspondencia con los géneros del soporte analógico.

Para autores como Cassany (2013), Morales y Espinoza (2013) y Levratto (2014), cuando se habla de textos en soporte digital no nos podemos referir únicamente a los hipertextos, ni a los géneros discursivos mencionados, ya que en la Red estos conviven con textos transferidos del soporte impreso. Esta hibridación hace que sea mucho más complejo leer en pantallas.

\subsection{Características de los lectores}

Los textos digitales exigen al sujeto un papel más protagónico, activo y dinámico en el proceso de lectura (Landow, 1995; Prensky, 2001; Jenkins, 2008; Díaz, 2009; Piscitelli, 2011). Landow (1995) indica que en el formato electrónico se evidencia un cambio de visión del texto unitario al texto disperso. Esto implica que el texto se representa a través de distintas secuencias, con múltiples inicios y finales, que exigen que el lector tome decisiones constantemente, que ajuste su carta de navegación dependiendo de sus propósitos, que acuda a distintos medios y dispositivos y que, además de consumir, produzca información trabajando en 
red (Jenkins, 2008). Una mayor libertad en la exploración de la información y en la toma de decisiones implica también un mayor compromiso por parte del lector, quien debe desarrollar las competencias necesarias para abordar de manera pertinente los textos, atendiendo a sus necesidades informativas (Argüello, 2012).

\section{Metodología}

Esta investigación se inscribió en un enfoque mixto, que se basa tanto en la observación y descripción de los fenómenos en su contexto natural, como en su cuantificación. Se utilizó un diseño no experimental de tipo transversal (McMillan y Schumacher, 2005).

\subsection{Población y muestra}

Este estudio se realizó en el marco de una asignatura de lectura, dirigida a estudiantes de primer semestre de distintos programas académicos de Ingeniería de una universidad de la ciudad de Cali, Colombia. El número total de estudiantes inscritos en los distintos grupos de la asignatura fue de 311. Se calculó una muestra representativa para esta población, cuyo resultado fue 212. El porcentaje de error calculado fue 5, el nivel de confianza 99\% y la distribución de respuestas 50\%. Para elegir los estudiantes se realizó un muestreo aleatorio estratificado por carreras.

\subsection{Técnicas de recolección de información}

- Cuestionario en línea sobre prácticas de lectura digital. Este instrumento, que incluyó 30 preguntas, indagó por los dispositivos que usan los estudiantes, sus propósitos de lectura, los tipos de textos que leen, las estrategias que usan, las dificultades que encuentran y las orientaciones que reciben por parte de la universidad.

- Análisis documental de diarios. En la asignatura se solicitó a los estudiantes que registraran en un diario toda la información relacionada con sus prácticas de lectura en los distintos cursos y actividades de la universidad. Al final del semestre se eligieron 20 diarios al azar y se identificó en ellos información relacionada con la lectura digital.

- Grupos de discusión. Se usaron con el propósito de aclarar o profundizar en la información recolectada con los otros instrumentos.

El cuestionario fue validado a través del juicio de ocho expertos y de un pilotaje con diez sujetos pertenecientes al universo poblacional, quienes evaluaron el instrumento a partir de cuatro indicadores: coherencia con los objetivos de la investigación, coherencia interna, claridad y ajuste de las preguntas a la audiencia y extensión del cuestionario. Para garantizar la validez de los resultados se consideró 
la triangulación en la recopilación de los datos y su análisis. Se digitalizaron los diarios y se transcribieron los grupos de discusión para retomar citas literales y analizarlas en el contexto en el cual fueron producidas.

Se utilizaron técnicas de estadística descriptiva, con apoyo del spss v.22, para el manejo de datos del cuestionario, así como tablas de contingencia y pruebas de significación para establecer relaciones entre variables demográficas (edad, sexo, carrera) y prácticas de lectura (soporte preferido, tipos de texto, multitarea). Para la información recolectada a partir de los diarios y de los grupos de discusión, se usó la técnica de análisis de contenido (Bardin, 1996), con apoyo del Atlas.Ti 7.0.

\section{RESUlTADOS Y ANÁLISIS}

El $72 \%$ de los participantes fueron hombres y el 28\% mujeres, todos pertenecientes a programas de Ingeniería. La edad promedio fue 17,6, en un rango entre 16 y 19 años. La mayoría de los encuestados pertenecía a un estrato socioeconómico medio. Se encontró que todos los sujetos contaban con al menos un dispositivo electrónico para uso personal, varios de ellos tenían dos o más dispositivos. Predominó el uso del computador de escritorio (85\%) y el celular (82\%), seguidos del portátil (77\%) y las tabletas (66\%), mientras que los e-readers apenas eran usados por un $8 \%$ de la muestra.

A continuación se presentan categorías de análisis que agrupan información proveniente de la aplicación de los distintos instrumentos ${ }^{1}$.

\subsection{Tipos de lectura}

Las más frecuentes fueron la social-recreativa y la informativa; apareció con menor frecuencia la académica y la literaria fue la menos habitual. Los estudiantes dieron cuenta de los dispositivos que usan dependiendo de cada lectura: en la informativa usan predominantemente el celular (76\%); en la académica, el computador de escritorio (86\%); en la social-recreativa, el celular (81\%); en la literaria, la tableta (26\%). Estos resultados coinciden con diversos antecedentes investigativos, que evidencian que los jóvenes leen con mucha frecuencia en pantallas, pero principalmente para prácticas vernáculas relacionadas con propósitos sociales o recreativos (Olmo, 2010; Cassany, 2013).

1. Los diarios se identifican con la letra D y van desde D1 hasta D20. Los grupos de discusión se identifican con la letra G y los estudiantes que intervinieron con la letra E, van desde GE1 hasta GE17. 


\section{2. ¿En qué soporte leen?}

Los estudiantes indican que leen ambos soportes (79\%), pero prefieren la lectura en soportes impresos (Gráfico 1).

\section{GRÁFICO 1}

¿En qué soporte leen y qué soporte prefieren?

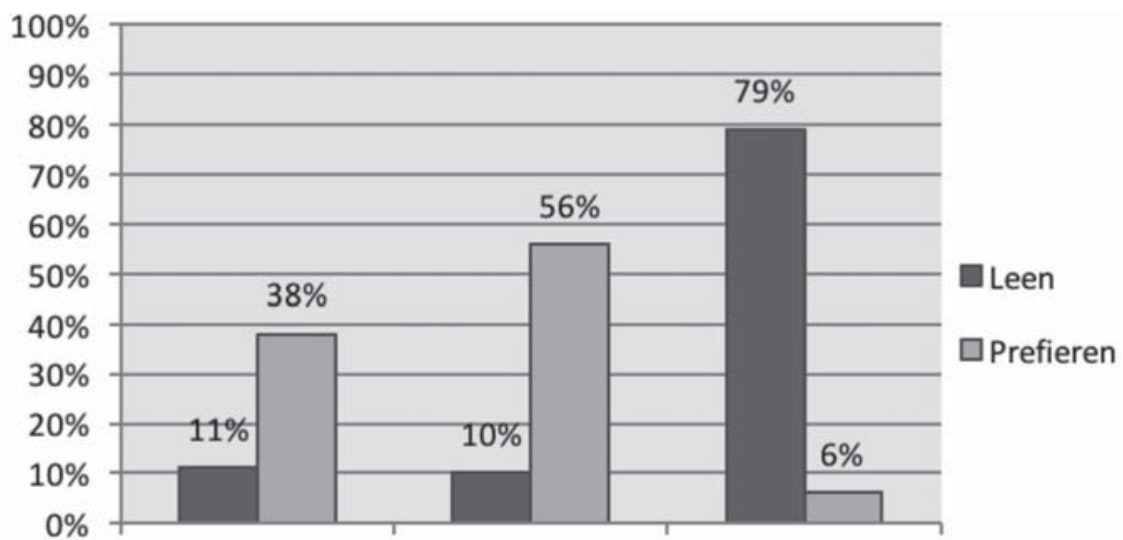

Pantalla

Papel

Ambos

En los grupos de discusión y en los diarios se evidencia que si la lectura es extensa se prefiere en papel, aunque en algunos casos se prefiere digital para economizar en los gastos de impresión. La preferencia por lo digital está condicionada por distintos factores, entre ellos la búsqueda rápida de información, la extensión del texto, la multitarea y la presentación de información en modalidades distintas a la verbal. Se lee también en pantallas si la tarea implica conocer de manera general la información y si se cuenta con poco tiempo.

GE2: Si es para buscar algo, me parece más rápido en Internet. Ya si es un libro o algo así gordito, es mejor imprimirlo o buscarlo en la biblioteca, porque cansa mucho leer en el computador... En la pantalla es más fácil entender por una razón: casi siempre hay imágenes o videos, cosas que un libro no tiene tan marcadas. Además, en la pantalla es como más corto.

\section{3. ¿Qué leen en soporte digital?}

Esta categoría indagó por las tipologías textuales consultadas con más frecuencia por los estudiantes en la Red (Gráfico 2). 
GRÁFICO 2

¿Qué leen en soporte digital?

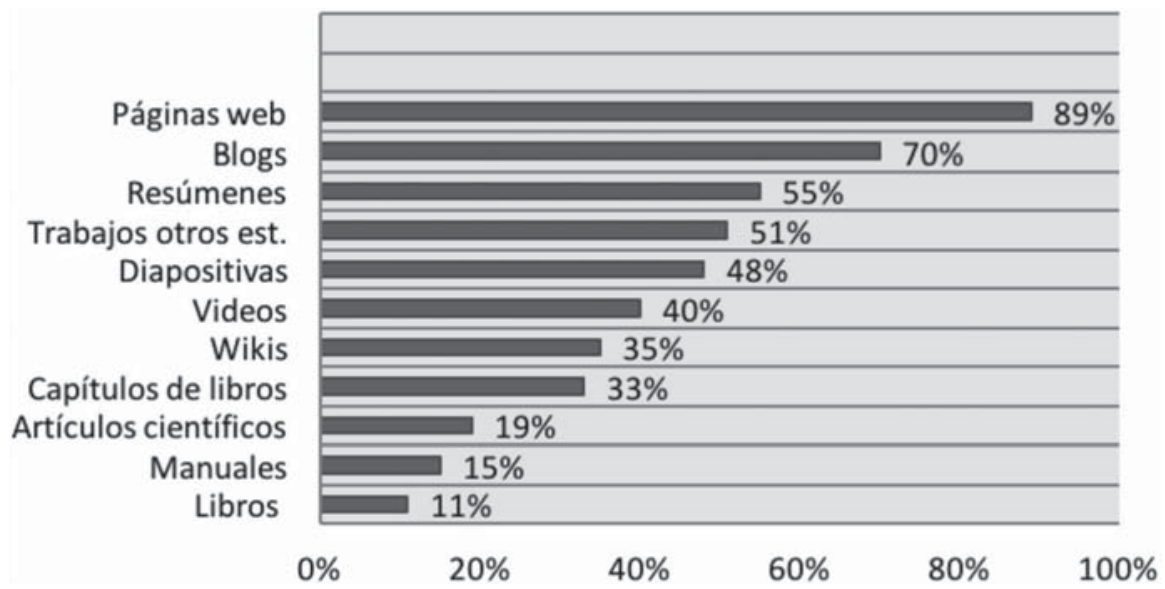

De acuerdo con la información presentada en la categoría anterior, es entendible que aparezcan pocos libros y manuales en la lectura digital, ya que la extensión del texto es uno de los factores que influye en la elección del soporte impreso. Las pantallas son más un mecanismo de referencia para los estudiantes, es decir, suelen usarse para encontrar información muy específica, pero no para profundizar en los textos (Noorhidawati y Gibb, 2008; Argüello, 2012).

En el Gráfico $2^{2}$ se evidencia que los estudiantes leen principalmente páginas web, blogs y resúmenes, seguidos de trabajos de otros estudiantes, diapositivas y videos. Pérez y Rincón (2013), en su investigación Para qué se lee y se escribe en la universidad colombiana, también encontraron un alto porcentaje (79\%) de lectura de páginas web y de blogs por parte de los alumnos universitarios.

Sobre el uso de los blogs, los estudiantes de los programas de Ingeniería de Sistemas y de Ingeniería Electrónica indican que para ellos es importante consultar información actualizada y esto se facilita en formatos tipo wikis, blogs o foros de expertos:

D19: No se encuentra bibliografía sobre software de notación musical. Para construir la historia con los principales programas y desarrollos tuve que acudir a Wikipedia, a varias páginas comerciales y a blogs en los que se contaban experiencias. No hay libros sobre eso, pero para mi proyecto es importante conocerlo.

2. En la mayoría de los gráficos los valores sobrepasan el $100 \%$, esto se debe a que en el cuestionario se permitía a los estudiantes marcar varias respuestas. 
Estas reflexiones de los estudiantes apoyan la idea de que los modos de leer, independientemente del soporte, necesitan de la orientación de los expertos en las disciplinas (Carlino, 2003). Por ejemplo, la consulta de páginas que no siempre cumplen criterios de confiabilidad podría ser sancionada por profesores de lengua o por otras instancias institucionales que desconocen los modos particulares de acceder y usar la información en áreas como Ingeniería de Sistemas.

Respecto a los otros documentos que suelen consultar los estudiantes (resúmenes, otros trabajos, diapositivas), se observa que son, predominantemente, fuentes secundarias. Estas pueden constituir un riesgo cuando no se toman como un apoyo para comprender la información, sino que son el reemplazo de las fuentes primarias, lo cual podría deberse, en cierta medida, a las demandas de los profesores, quienes suelen pedir síntesis de las lecturas.

GE1: Aunque sé que no es un buen método, busco trabajos que han hecho otros porque me parece más fácil y, además, muchos trabajos que uno tiene que hacer ya alguien más los ha hecho, entonces uno puede ahorrar.

Los estudiantes también indicaron que acuden a modalidades audiovisuales, en este caso diapositivas y videos, porque las perciben como más entretenidas y más fáciles de comprender en ciertas tareas:

GE5: Entiendo mejor si hay ya hechas unas diapositivas sobre el tema, es más rápido y casi siempre es más fácil. Soy más visual, me gustan los videos y los gráficos, el texto largo me aburre.

Como puede evidenciarse, las prácticas actuales de los estudiantes exigen el desarrollo de competencias para leer distintos tipos de textos, de signos y de medios. Esta realidad requiere de intervención y guía desde el contexto educativo (Kress, 2005; Barbero, 2008; Dussel, 2009; Cassany, 2013). No podemos considerar que el estudiante lo aprende espontáneamente, pues el uso frecuente de las tecnologías no implica necesariamente el desarrollo de competencias, si no se pasa por la reflexión y la conciencia (Dillon, 1994).

\section{4. ¿Quién selecciona los textos?}

Aunque el profesor asigna y recomienda textos, es el estudiante quien suele seleccionar los textos digitales (Gráfico 3). 
GRÁFICO 3

¿Quién selecciona los textos que leen?

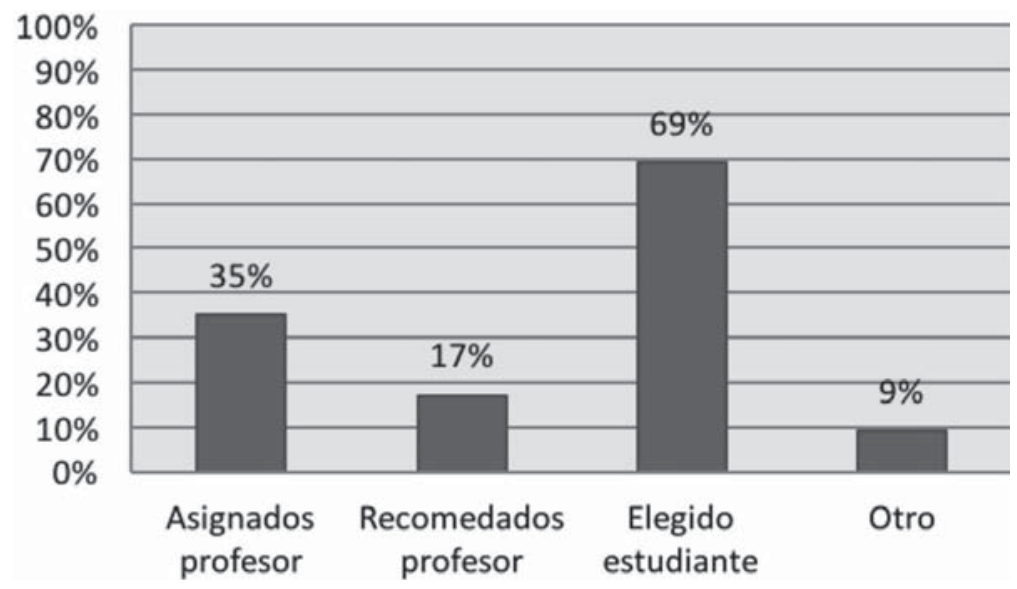

GE6: Busco los textos que necesito para estudiar para los exámenes o cuando me dejan un taller. A veces los profesores nos dejan el material en Blackboard, pero no siempre es así.

De acuerdo con los estudiantes, los profesores comparten algunos textos por correo electrónico o mediante la plataforma virtual de la universidad, pero son más frecuentes las asignaciones de textos impresos en los cursos. Sin embargo, se evidencia que los estudiantes sí leen en línea y que son ellos mismos quienes eligen los textos.

Al respecto, Perelman et al. (2008) y Coscarelli (2009) afirman que se corren ciertos riesgos cuando los estudiantes seleccionan los textos sin la orientación del profesor. Esto puede derivar en la consulta de fuentes poco confiables, sobre todo para aquellos que apenas están ingresando a la cultura académica y para quienes evaluar fuentes de información no es una práctica habitual. Cuando se ingresan palabras clave en un buscador, aparece una gran cantidad de fuentes, sin un filtro por grado de confiabilidad, en ocasiones sin datos de autoría, fecha u otros parámetros que ayuden al estudiante a establecer juicios apropiados.

\section{5. ¿Para qué leen en soporte digital?}

Los estudiantes leen en soporte digital principalmente para atender las demandas formales de la asignatura: escribir un texto académico, preparar exposiciones, estudiar para un parcial o responder a las preguntas del profesor (Gráfico 4). 
GRÁFICO 4

¿Para qué leen en soporte digital?

Escribir un texto académico

Preparar exposiciones

Estudiar para un parcial

Responder a preguntas profesor

Preparar un tema para una clase

Ampliar los contenidos vistos

Entender un tema complejo

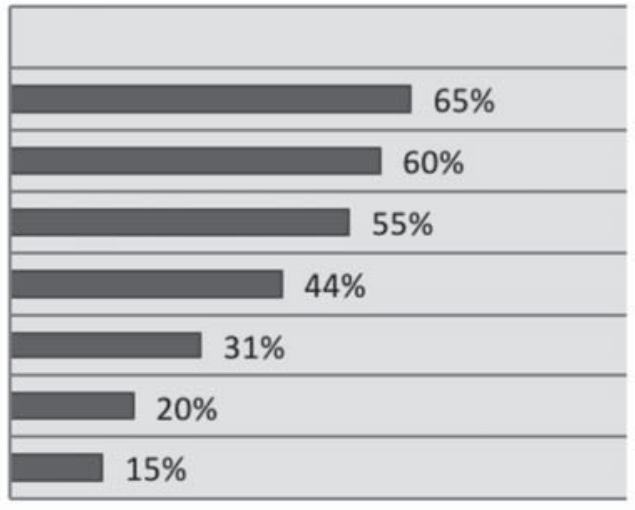

$\begin{array}{llllll}0 \% & 20 \% & 40 \% & 60 \% & 80 \% & 100 \%\end{array}$

D2: Como tenía que hacer unas fichas técnicas sobre puentes, tuve que buscar mucha información sobre este tipo de construcciones en todo el mundo.

GE11: Tenemos clases en las que casi cada semana hay un taller y hay que buscar las respuestas y leer bastante para poder responder a las preguntas.

Estos propósitos de lectura son percibidos por los estudiantes como una responsabilidad para atender a las prácticas evaluativas, ya que, como indica Carlino (2005), la evaluación determina una especie de 'currículo oculto' y concentra la atención de los estudiantes en unas actividades y prácticas particulares en la asignatura. Pocos usan la lectura para preparar las clases, ampliar los temas o reforzar sus conocimientos, lo que puede significar que se aprovecha poco el potencial epistémico de la lectura.

\section{6. ¿Por qué leen en soporte digital?}

Esta categoría indagó sobre las principales razones por las que los estudiantes leen en pantalla (Gráfico 5). 
GRÁFICO 5

¿Por qué leen en soporte digital?

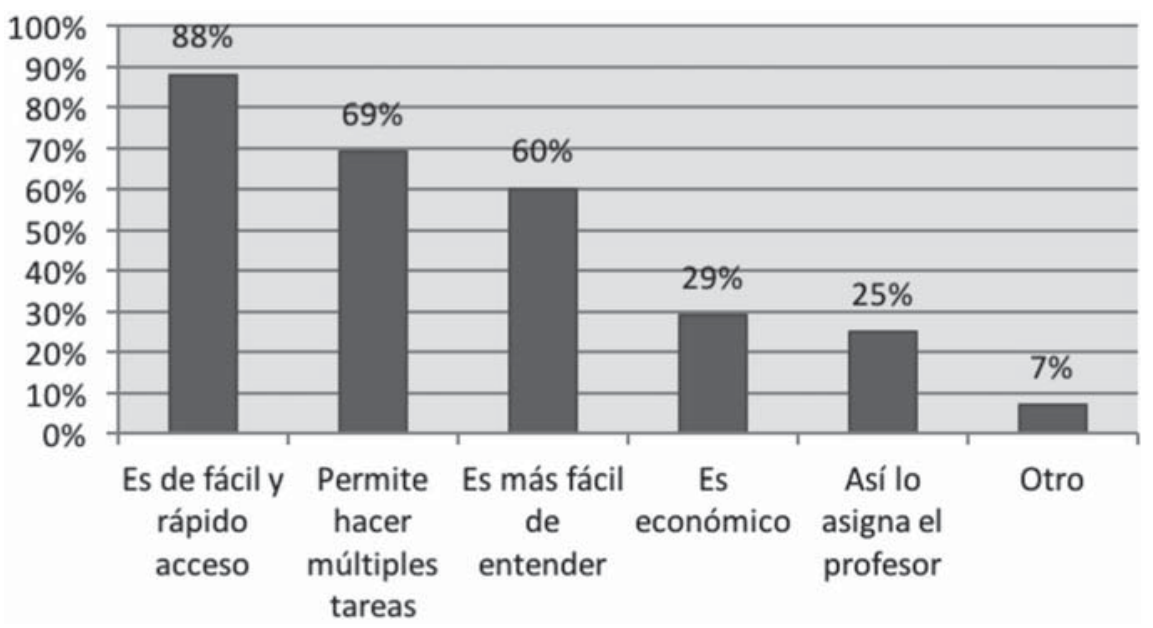

La primera razón es el rápido acceso a la información. Los estudiantes interactúan a diario con las pantallas y muchas veces las transportan de un lugar a otro, por lo que su uso es inmediato, sin restricción de horarios o espacio (Díaz, 2009). Además, a diferencia del libro, las pantallas son portadoras potenciales de muchos textos.

GE10: Busco en el iPhone cuando estoy de afán y necesito algo, leo en el MíO (transporte masivo), aprovecho mi tiempo.

D5: No se necesita ir a la biblioteca cuando Google lo tiene todo.

La segunda razón es que la pantalla permite realizar varias tareas al tiempo. La tercera razón es que consideran que los textos digitales son más sencillos que los impresos, principalmente por los distintos formatos en los que se presenta la información.

GE2: ... En la pantalla es más fácil entender por una razón: casi siempre hay imágenes o videos, cosas que un libro no tiene tan marcadas. Además, en la pantalla es como más corto.

D9: Manejar Python en la clase es muy complicado, el profesor explica muy rápido. Es más sencillo si se miran los manuales en Internet y si se siguen los tutoriales. Está paso por paso cómo usarlo. 


\section{7. ¿Cómo buscan información?}

Cerca de la mitad indican que usan el buscador Google y que tienen criterios para evaluar las fuentes (Gráfico 6). Sin embargo, esta información no es coherente con lo que se plantea en los grupos de discusión o la información hallada en los diarios, en donde indican que el principal problema que tienen para leer en pantallas es evaluar la confiabilidad de las fuentes.

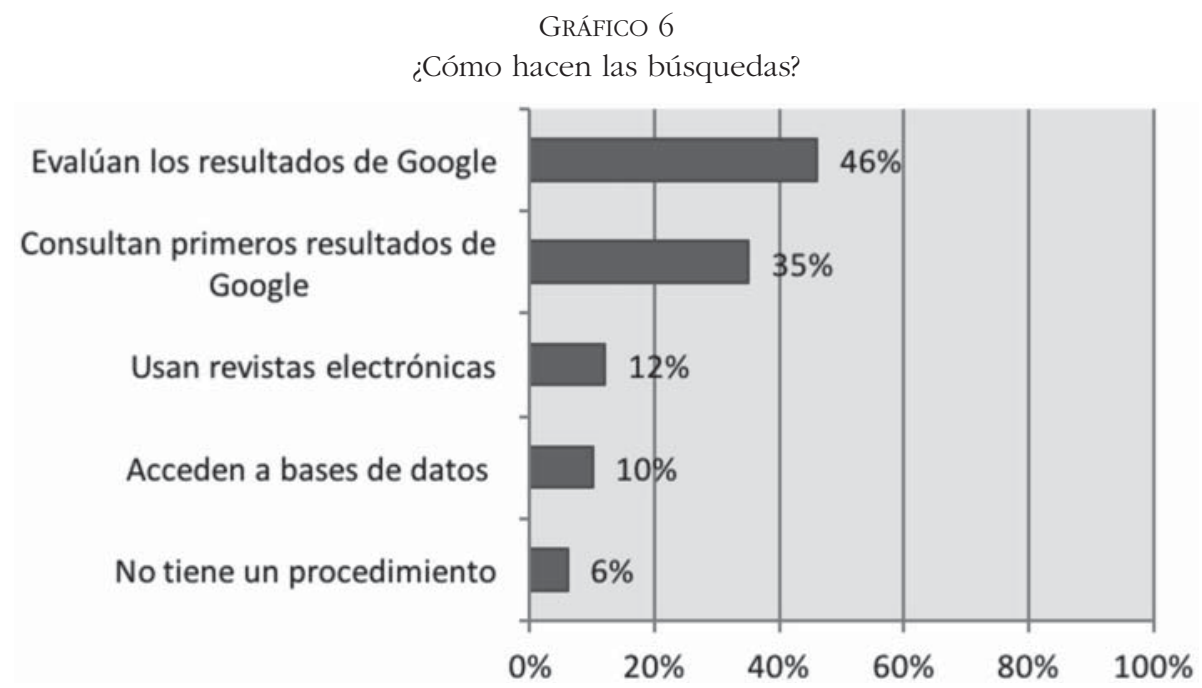

GE13: ... Los [resultados] que te aparecen primero son los que más se relacionan con tu tema y esos son los que puedes coger.

Estas prácticas de búsqueda coinciden con las halladas por Figueroa et al. (2007), quienes encontraron que los alumnos usan Google u otros navegadores en la Red, que suelen hacer búsqueda por tema (con palabras clave) y elegir los primeros resultados. Perelman et al. (2009) encuentran resultados similares y explican esta situación indicando que las fuentes electrónicas no tienen los rasgos paratextuales que tienen las impresas (carátula, forma, portada) y que esta homogeneidad en la superficie puede llevar a que los estudiantes las consideren como iguales en su nivel de confiabilidad. Otra razón es que los buscadores arrojan datos en orden de frecuencia de uso y estos resultados pueden ser "pertinentes» en cuanto tienen una relación directa con el tema, pero pueden ser poco adecuados respecto a la veracidad y a la profundidad con la que se aborda la información. 


\section{8. ¿Cómo leen en soporte digital?}

Los estudiantes indican que suelen hacen exploraciones generales de información o leer partes específicas de los textos. No suelen leer el texto completo, releerlo o leerlo en profundidad (Gráfico 7). Si el texto lo permite, los alumnos exploran algunos vínculos y consultan otras fuentes de información. Cuando se les pregunta acerca de estas otras fuentes, indican que suelen ser las planteadas por el mismo texto que leen (hipervínculos) o fuentes que están acostumbrados a consultar, entre ellas Wikipedia.

Cuando se les pregunta si consideran que sus estrategias de lectura digital son adecuadas, el 42\% indica que sí y el 58\% considera que no.

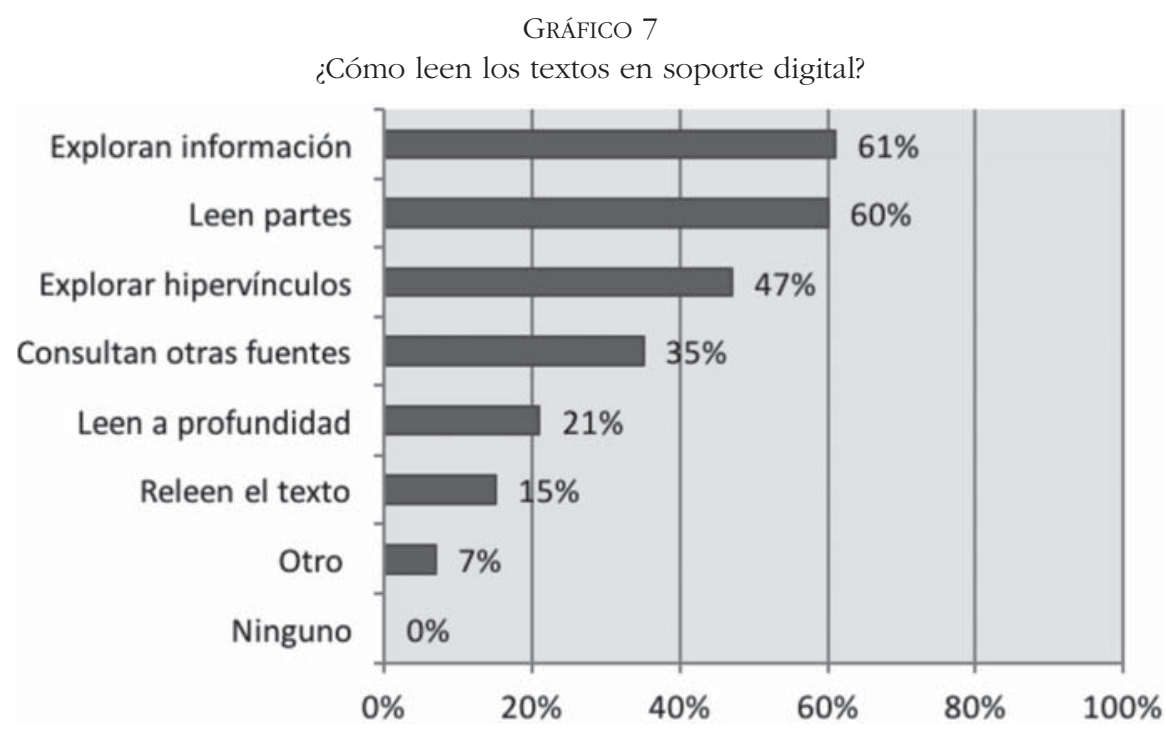

GE9: Wikipedia, por ejemplo, siempre tiene enlaces para ampliar información, son las referencias y uno puede ampliar, entonces se va a revisar esos datos.

D7: No hay que leer todo, porque en Google inclusive puedes llegar exactamente a lo que estás buscando. Yo entro a la página, doy CTRL+F y en buscar pongo la palabra o frase y así puedo revisar solo lo que me interesa.

Puede ser que la fatiga visual y la facilidad de acceder a otras fuentes lleven a un escaneo general de la información y al llamado "zapping" o saltos de una información a otra (Cassany, 2013; Morduchowicz, 2013). En este aspecto, se puede retomar la noción de lectura extensiva planteada por Cavallo y Chartier (1997), quienes contraponen esta idea a la clásica lectura intensiva, propia de momentos históricos en los que los lectores se sumergían en los libros y llegaban hasta sus 
profundidades. La lectura extensiva, por su parte, es más libre; la información se puede presentar de forma segmentada y discontinua, se atiende más al fragmento que a la totalidad, se busca y se usa información muy puntual. Esta dispersión de la información, característica del hipertexto, puede ser asumida como un elemento negativo cuando se compara con las prácticas tradicionales, o puede asumirse como una característica positiva cuando se concibe como un reto para poner en juego procesos cognitivos de alto nivel, que permiten ajustarse a las realidades actuales de la sociedad de la información. Esto depende, como lo plantea Dillon (1994), de cuáles son los propósitos y orientaciones de la lectura desde el contexto educativo.

De todas formas, se debe considerar que los estudiantes universitarios tampoco tienen como práctica frecuente en papel leer en profundidad o leer los textos varias veces. Esto puede confirmarse en los diarios revisados, pues varias de las anotaciones muestran que los estudiantes leen los textos una sola vez o hacen exploraciones generales de la información:

GE7: Es supervivencia. En semanas de parciales estamos muertos, si me ponen a leer una fotocopia yo me guío por los títulos y el resumen...

\section{9. ¿Realizan otras actividades mientras leen en soporte digital?}

El 79\% de los encuestados afirmó llevar a cabo otras actividades mientras lee en pantalla. También indican que necesitan escuchar música o jugar para distraerse y no fatigarse con la lectura. Otros afirman que tienen la capacidad de hacerlo y que, además, les ayuda a aprovechar el tiempo.

GE7: Me gusta jugar, me ayuda a distraerme, solo paro 10 o 15 minutos. También escucho música clásica o en inglés mientras leo.

GE12: Sí, el chat sí lo uso, pues el de Facebook, pero no siempre es por "vagancia», allí uno le habla a algún compañero para preguntarle las dudas o saber bien qué hay qué hacer o hacer otro trabajo, etcétera.

El 49\% de los encuestados afirma que también lleva a cabo otras actividades mientras lee en papel, lo cual indica que la multitarea no es una característica exclusiva de las pantallas, aunque sí se ve favorecida y aparece con más frecuencia en este soporte.

El Gráfico 8 muestra las actividades que suelen acompañar a la lectura digital: 
GRÁFICO 8

¿Qué actividades acompañan a la lectura?

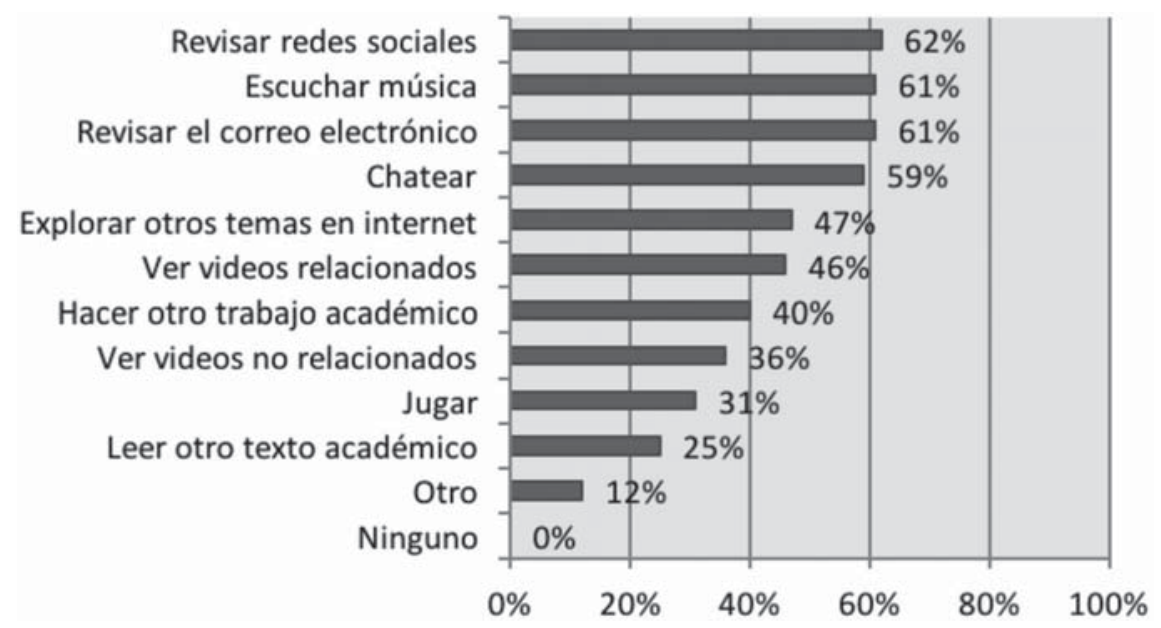

Las actividades realizadas por los estudiantes son muy variadas. Las de mayor frecuencia (redes sociales, música, correo y chat) no tienen necesariamente una relación directa con la lectura, aunque algunos estudiantes afirman que por estos medios pueden establecer algún contacto con compañeros para resolver alguna duda o realizar un trabajo. Aparecen, con menor frecuencia, actividades que se relacionan directamente con propósitos académicos (ver videos sobre el tema, hacer otro trabajo académico).

Casi la mitad de los estudiantes reconoce que la multitarea disminuye la eficiencia en la lectura, pues implica una mayor inversión de tiempo, pero pocos consideran que afecta negativamente la comprensión de los textos. De igual manera, no siempre se realizan otras actividades mientras se lee en pantalla, ya que esto se ve condicionado por el tipo de tarea. Hay multitarea si el texto es muy sencillo (57\%) o si no es interesante para los estudiantes (52\%).

Al respecto, Morduchowicz (2013) plantea que no se sabe con seguridad si el procesamiento en paralelo o multitarea tiene implicaciones negativas en los procesos de aprendizaje. Es posible que los jóvenes de esta generación incorporen estas prácticas y que sean el reflejo de las características de la sociedad del conocimiento: rápida, dispersa, convergente. Lo que sí es claro es que la mayoría de los jóvenes lo considera como algo 'natural' y que en esta práctica se desdibujan los límites entre las actividades recreativas y las académicas. 


\subsection{0. ¿Qué dificultades identifican cuando leen en pantallas?}

Esta categoría indagó acerca de las dificultades que los estudiantes identifican cuando leen en pantallas (Gráfico 9).

\section{GRÁFICO 9}

¿Qué dificultades identifican cuando leen?

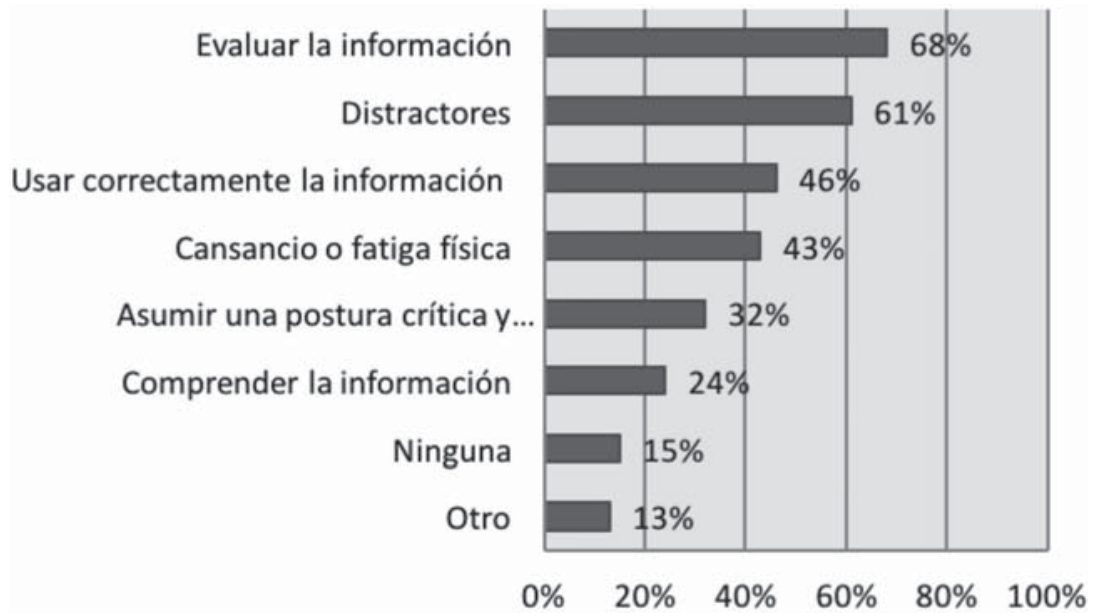

Para los estudiantes, el mayor desafío es evaluar la confiabilidad de la información presentada en las distintas fuentes. Aparece como segunda dificultad la presencia de distractores. Atendiendo a los resultados de la categoría anterior, se puede afirmar que la presencia de distractores se relaciona con una mayor inversión de tiempo y no con problemas para comprender los textos. El tercer problema identificado es el uso correcto de la información y las posibilidades de incurrir en plagio.

Otro problema es el cansancio o fatiga visual, que coincide con los hallazgos de distintos autores (Dillon, 1994; Nielsen, 1995). Aunque se ha avanzado en los dispositivos tecnológicos, la fatiga visual es un problema que todavía no se resuelve totalmente.

\subsection{1. ¿Qué orientaciones reciben respecto a la lectura digital?}

En esta categoría se indagó por los apoyos que los estudiantes reciben actualmente para leer en pantallas y quién proporciona esos apoyos (Gráfico 10). 
GRÁFICO 10

¿Quién orienta la lectura en soporte digital?

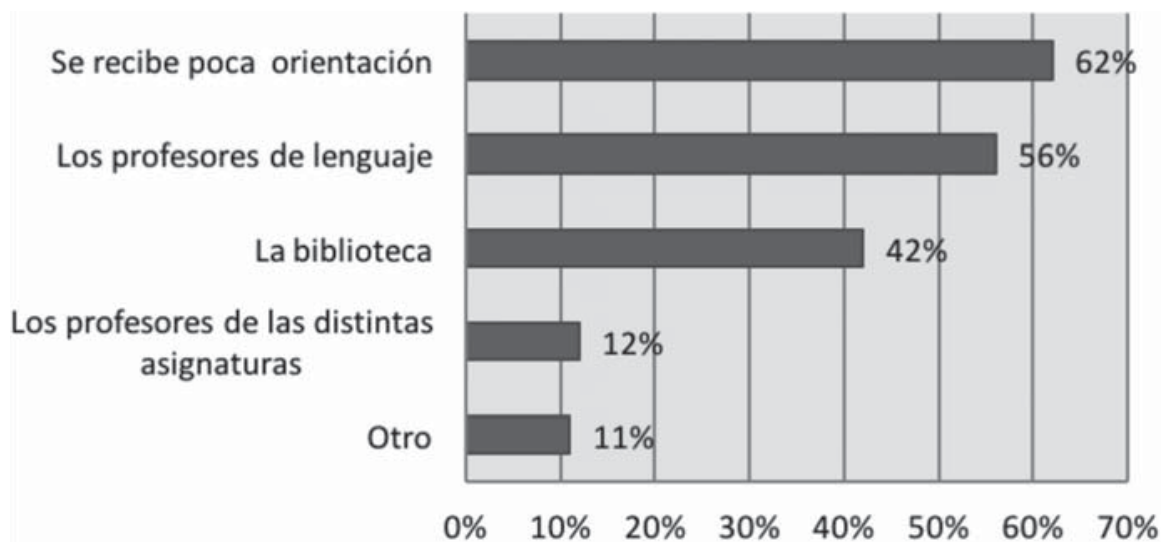

Más de la mitad de los estudiantes considera que no hay orientación respecto a la lectura digital.

GE15: Muy poco... Creo que es algo que hacemos solos. Uno se va enfrentando y va aprendiendo.

Se evidencia también que el mayor apoyo identificado es el de los profesores de lenguaje. Esto se debe a que los estudiantes estaban cursando una asignatura introductoria de lectura cuando se aplicó el cuestionario, aunque este tipo de cursos no garantizan el abordaje de la lectura digital, pues trabajan sobre los procesos de lectura académica en general.

Se identifican también aportes de la biblioteca, aunque los estudiantes indican que asisten muy poco.

GE5: De la biblioteca hacen muchas cosas, sino que les falta llegar más al estudiante. Hay campañas de no hacer o cometer plagio, han hecho hasta charlas... de pronto hay que saber llegar mejor a los jóvenes. Hasta que no es algo que uno necesita, uno no asiste.

Los profesores de las disciplinas no aparecen como orientadores de la lectura digital. Este hecho es inquietante, si se reconoce que las competencias informacionales y los modos de leer no son un conjunto de habilidades genéricas (Carlino, 2005), sino que varían en las disciplinas, tal como se evidenció en la categoría ¿QQué leen en soporte digital?'.

Respecto a los apoyos recibidos, los estudiantes mencionan que son pocos. En el grupo de discusión los estudiantes indican que algunas veces los profesores les advierten sobre los riesgos del plagio: 
GE16: Hay una súper presión con todo este cuento del plagio.

GE17: Sí, todo el tiempo asustan, pero tú estás acostumbrado a unas cosas en el colegio. En el colegio te ponían a investigar qué era el genoma humano y lo podías tomar de Wikipedia y ya. Ahora no es así.

Cuando se les pregunta si consideran pertinente o si les gustaría recibir más orientación sobre la lectura digital, el 78\% responde que sí.

Se indagó por las estrategias que considerarían más efectivas para proporcionar los apoyos para la lectura en pantallas (Gráfico 11):

\section{GRÁFICO 11}

¿Qué estrategias consideran efectivas para brindarles apoyo?

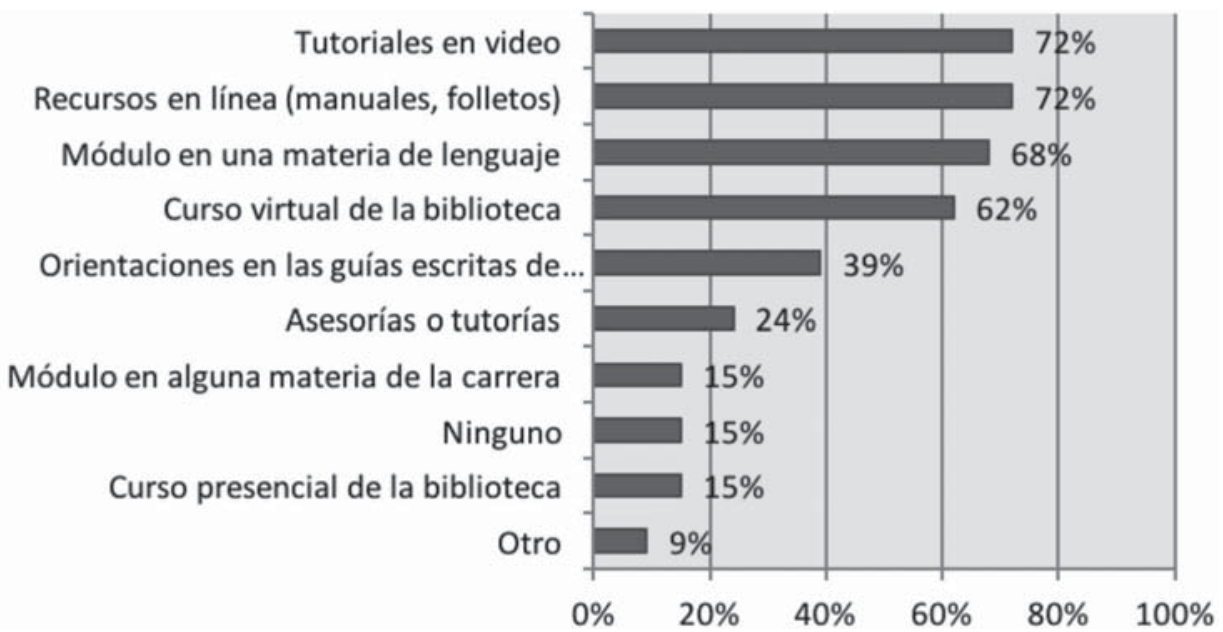

En relación con las estrategias, se observa que los estudiantes privilegian aquellas que les permiten procesos de autoaprendizaje: tutoriales en video y recursos en línea. Esta es una característica propia de esta generación, cuyo desarrollo de prácticas letradas vernáculas y cuyo dominio de las herramientas tecnológicas suele ser autónomo (Cassany, 2013).

Le siguen en orden de frecuencia un módulo en una asignatura de lenguaje, donde se considera propicio abordar la lectura digital y un curso virtual de biblioteca. Al respecto, en el grupo de discusión un estudiante plantea:

GE9: Tienen que ser cosas muy puntuales. Los cursos largos aburren y tiene que ser sobre cosas que uno realmente necesite porque se lo exigen en la universidad.

Aunque no aparecen predominantemente las orientaciones en las asignaturas disciplinares, posiblemente porque los estudiantes aún no son conscientes de que los modos de leer son específicos en cada área, algunos estudiantes (39\%) 
identificaron que es importante recibir orientaciones particulares en cada tarea de lectura. Esta identificación es mayor por parte de aquellos que ya se han enfrentado a estas características:

GE17: Me parece que las guías o las indicaciones del maestro son necesarias, porque hay temas que el profesor es quien conoce la bibliografía.

\subsection{Relaciones entre las características de la muestra y las prácticas de lectura digital}

Esta categoría indaga por las relaciones estadísticamente significativas que se establecen entre algunas de las variables descritas.

\subsubsection{Edad y prácticas de lectura digital}

Se encontró una relación estadísticamente significativa entre la edad y la preferencia de lectura. En la prueba ANOVA de un factor, una vez verificadas las condiciones de normalidad y de homocedasticidad, se halló un valor inferior a 0,05, por lo que se rechaza la igualdad en las medias de los grupos (Tabla 1).

TABLA 1

ANOVA de un factor. Edad* Preferencia de lectura

\begin{tabular}{|l|r|r|r|r|r|}
\hline & Suma de cuadrados & gl & Media cuadrática & F & Sig. \\
\hline Inter-grupos & 38,890 & 2 & 19,445 & 25,682 &, 000 \\
Intra-grupos & 158,243 & 209 &, 757 & & \\
Total & 197,132 & 211 & & & \\
\hline
\end{tabular}

Se aplicó un análisis post hoc con la prueba HSD de Tukey para identificar los grupos en los que se encuentran concentradas las diferencias. Como se muestra en la Tabla 2, hay significación por debajo de 0,05 (lo que implica que se rechaza la igualdad de medias) entre el soporte papel y pantalla; entre papel y ambos, y entre pantalla y papel. No se observan diferencias entre las opciones pantalla y ambos. 
TABLA 2

Comparaciones múltiples. Edad* Preferencia de lectura

\begin{tabular}{|c|c|c|c|c|c|c|}
\hline \multirow{2}{*}{$\begin{array}{l}\text { (I) ¿En qué soporte } \\
\text { prefieren leer? }\end{array}$} & \multirow{2}{*}{$\begin{array}{l}\text { (J) ¿En qué soporte } \\
\text { prefieren leer? }\end{array}$} & \multirow{2}{*}{$\begin{array}{l}\text { Diferencia de } \\
\text { medias }(1-J)\end{array}$} & \multirow[t]{2}{*}{ Error típico } & \multirow[t]{2}{*}{ Sig. } & \multicolumn{2}{|c|}{ Intervalo de confianza al 95\% } \\
\hline & & & & & Limite inferior & Limite superior \\
\hline \multirow{2}{*}{ Papel } & Pantalla & $864^{2}$ & .125 & .000 &, 57 & $\overline{1,16}$ \\
\hline & Ambos & $855^{\circ}$ & 264 &, 004 & 23 & 1,48 \\
\hline \multirow{2}{*}{ Pantalla } & Papel &,$- 864^{*}$ &, 125 &, 000 & $-1,16$ &,- 57 \\
\hline & Ambos &,- 009 & 269 & ,999 &,- 64 & ,63 \\
\hline \multirow{2}{*}{ Ambos } & Papel &,$- 855^{\circ}$ & 264 &, 004 & $-1,48$ &,- 23 \\
\hline & Pantalla &, 009 & 269 & ,999 &,- 63 &, 64 \\
\hline
\end{tabular}

Variable dependiente: Edad HSD de Tukey.

También se encontró una relación estadísticamente significativa entre la edad y la práctica de la multitarea. Para identificar esta relación se usó la prueba T de Student para muestras independientes. En los estadísticos de grupo se observa que las medias de los grupos (No y Sí) son distintas (Tabla 3):

TABLA 3

Estadísticos de grupo. Edad* Multitarea

\begin{tabular}{|l|l|r|r|r|r|}
\hline \multicolumn{7}{|c|}{ Estadisticos de grupo } \\
\hline \multirow{2}{*}{} & Multitarea & $\mathrm{N}$ & \multicolumn{1}{c|}{ Media } & Desviación típ. & $\begin{array}{c}\text { Error típ. de la } \\
\text { media }\end{array}$ \\
\hline \multirow{2}{*}{ Edad } & No & 45 & 18,27 &, 889 &, 133 \\
\cline { 2 - 7 } & Si & 167 & 17,04 &, 877 &, 068 \\
\hline
\end{tabular}

Los estadísticos de grupo nos muestran que, a menor edad, más multitarea (Tabla 4). 
TABLA 4

Prueba de muestras independientes. Edad* Multitarea

\begin{tabular}{|c|c|c|c|c|c|c|c|c|c|c|}
\hline & \multicolumn{2}{|c|}{$\begin{array}{c}\text { Prueba de } \\
\text { Levene }\end{array}$} & \multicolumn{7}{|c|}{ Prueba T para la igualdad de medias } \\
\hline & & \multirow[t]{2}{*}{$F$} & \multirow[t]{2}{*}{ Sig. } & \multirow[t]{2}{*}{$t$} & \multirow[t]{2}{*}{ बी } & \multirow[t]{2}{*}{$\begin{array}{c}\text { Sig. } \\
\text { (bilateral) }\end{array}$} & \multirow[t]{2}{*}{$\begin{array}{c}\text { Diferencia de } \\
\text { medias }\end{array}$} & \multirow[t]{2}{*}{$\begin{array}{l}\text { Error tip. de } \\
\text { la diferencia }\end{array}$} & \multicolumn{2}{|c|}{$\begin{array}{c}95 \% \text { Intervalo de } \\
\text { confianza para la } \\
\text { diferencia }\end{array}$} \\
\hline & & & & & & & & & Inferior & Superior \\
\hline \multirow{2}{*}{ Edad } & $\begin{array}{l}\text { Se han } \\
\text { asumido } \\
\text { varianzas } \\
\text { iguales }\end{array}$ & ,013 & ,908 & 8,328 & 210 &, 000 & 1,231 &, 148 & 939 & 1,522 \\
\hline & $\begin{array}{l}\text { No sehan } \\
\text { asumido } \\
\text { varianzas } \\
\text { iguales }\end{array}$ & & & 8,263 & 68,850 &, 000 & 1,231 & 149 & ,934 & 1,528 \\
\hline
\end{tabular}

\subsubsection{Sexo y prácticas de lectura digital}

Se establecieron relaciones entre sexo y preferencia de lectura (Tabla 5), así como entre sexo y práctica de multitarea (Tabla 6). En ambas se encontró que la significación en la prueba Chi-cuadrado de Pearson fue mayor a 0,05. De acuerdo con estos resultados, se puede afirmar que no hay evidencias suficientes para relacionar las variables mencionadas.

TABLA 5

Pruebas de Chi-cuadrado ¿En qué soporte prefieren leer?* Sexo

\begin{tabular}{|l|r|r|r|}
\hline & Valor & gl & Sig. asintótica (bilateral) \\
\hline Chi-cuadrado de Pearson & $1,625^{3}$ & 2 &, 444 \\
N de casos válidos & 212 & & \\
\hline
\end{tabular}

TABLA 6

Pruebas de Chi-cuadrado Multitarea* Sexo

\begin{tabular}{|l|r|r|r|r|r|}
\hline & Valor & gl & \multicolumn{1}{|c|}{$\begin{array}{c}\text { Sig. asintótica } \\
\text { (bilateral) }\end{array}$} & \multicolumn{1}{c|}{$\begin{array}{c}\text { Sig. exacta } \\
\text { (bilateral) }\end{array}$} & $\begin{array}{c}\text { Sig. exacta } \\
\text { (unilateral) }\end{array}$ \\
\hline $\begin{array}{l}\text { Chi-cuadrado de Pearson } \\
\text { Estadistico exacto de Fisher } \\
\mathrm{N} \text { de casos válidos }\end{array}$ &, $894^{\mathrm{a}}$ & 1 &, 344 & &, 454 \\
\hline
\end{tabular}

\subsubsection{Carrera y prácticas de lectura digital}

Para analizar esta relación se usaron tablas de contingencia (Tabla 7). Debido a que la pregunta sobre textos que se leen en pantallas era de respuesta múltiple, no fue posible hacer pruebas de significación estadística. 
TABLA 7

Tabla de contingencia Textos* Carrera

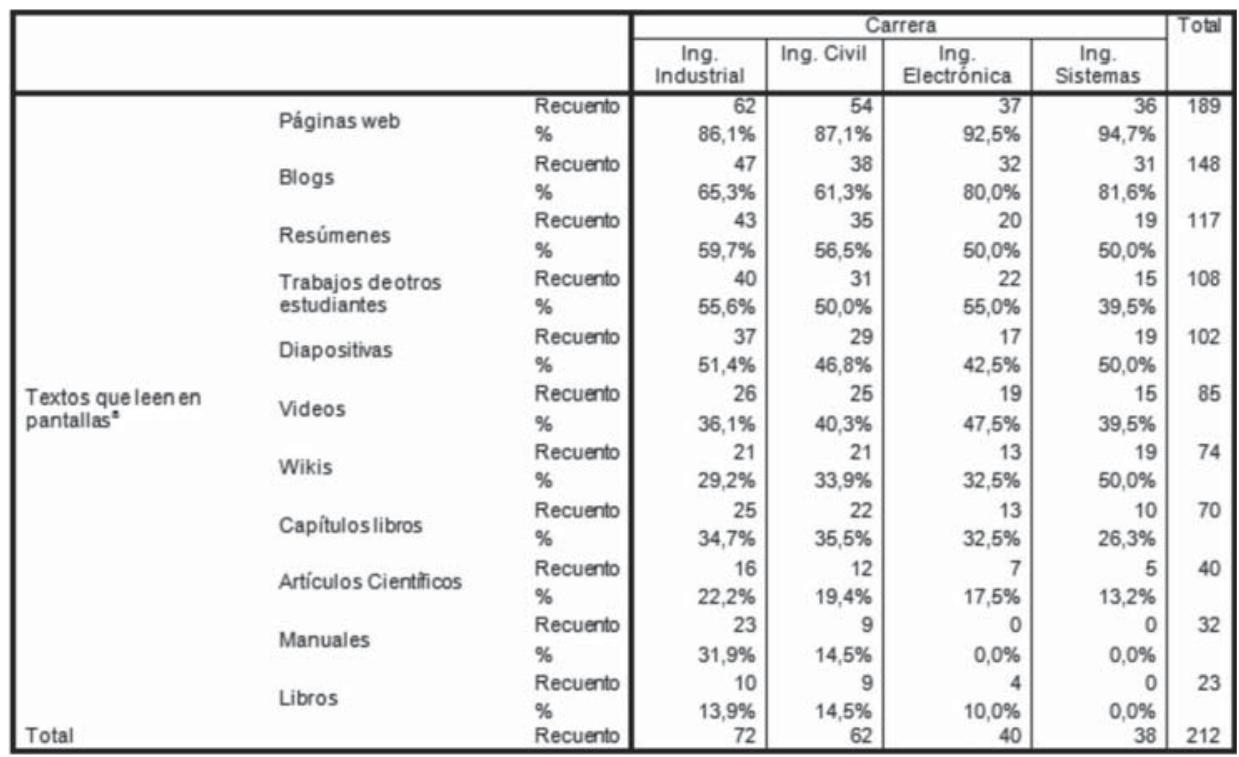

Se pueden destacar algunas diferencias porcentuales en la selección de los textos que se leen. Se encuentra que los estudiantes de Ingeniería Electrónica y de Sistemas consultan con más frecuencias blogs ( $80 \%$ y $81,6 \%$ respectivamente) que los estudiantes de Ingeniería Industrial y Civil (65,3\% y 61,3\%). También se evidencia que los estudiantes de Ingeniería de Sistemas consultan con más frecuencia wikis (50\%) que el resto de los participantes. Los manuales son más consultados por los estudiantes de Ingeniería Industrial (31,9\%). Finalmente, se evidencia que los estudiantes de Ingeniería de Sistemas encuestados no suelen leer libros ni manuales en pantallas.

\section{CONCLUSIONES}

Esta investigación se planteó como objetivo analizar las prácticas de lectura digital de estudiantes universitarios. Se encontró que los estudiantes leen tanto en pantalla como en papel y que esto depende, entre otros factores, del propósito de la lectura y de la extensión del texto. En pantalla suelen leer páginas web, blogs y textos secundarios como resúmenes, diapositivas y trabajos de otros estudiantes, acercándose poco a los textos canónicos de la academia: los libros y artículos científicos. Los estudiantes usan la Red principalmente como mecanismo de referencia, para buscar información puntual y de manera rápida, por lo que sus lecturas no 
suelen ser profundas ni completas y aparece con frecuencia el fenómeno de la multitarea. Los alumnos leen, principalmente, para atender a actividades evaluativas dentro de sus asignaturas disciplinares.

Los desafíos de lectura digital identificados por los estudiantes son la evaluación de la confiabilidad de las fuentes, el control de distractores y el uso adecuado de los datos para no incurrir en plagio. Los estudiantes indican que reciben pocos apoyos sobre cómo leer en pantallas y la mayoría considera pertinente recibir orientaciones al respecto. La responsabilidad es asignada a los profesores de lenguaje y a la biblioteca.

Al establecerse relaciones entre algunas de las prácticas, se encontró que la edad tiene una relación estadísticamente significativa con la práctica de multitarea y con la preferencia del soporte de lectura. La variable sexo no muestra evidencias de relación con estas prácticas. La carrera y los textos consultados en pantalla también se relacionan, encontrando que los estudiantes de Ingeniería de Sistemas y de Ingeniería Electrónica leen con mucha más frecuencia blogs que el resto de los participantes.

Sobre estos resultados es posible concluir que las prácticas de lectura involucran aspectos que no se reducen únicamente a la dicotomía pantalla/papel. El soporte digital y la posibilidad de estar en línea (Cassany, 2013) hacen que el texto cuente con otras características y que el sujeto lector también cambie; se requiere de un lector más activo, con mayores capacidades de evaluar la información, más selectivo y con competencias para interpretar distintos tipos de signos. En los siglos anteriores se necesitaban sujetos capaces de sumergirse en las interioridades del libro, pero el mundo contemporáneo parece necesitar sujetos que accedan rápidamente a la información y puedan manejarla, por lo que hay otras funciones y sentidos de la lectura (Barbero, 2008). La lectura en pantallas exige conocimientos y habilidades de comprensión que podrían aplicarse también a soportes impresos, pero requiere además de unas competencias específicas del medio digital.

$\mathrm{Al}$ respecto, aunque se considere que los jóvenes tengan un buen dominio de las tecnologías, no se debe dar por hecho que ya dominen las prácticas de lectura propias del contexto académico, pues ellos se mueven en el terreno de la comunicación privada, por lo que es necesario que los docentes establezcamos puentes entre las prácticas vernáculas y las que deseamos en la academia (Cassany, 2013).

Las orientaciones de los docentes deben tener en cuenta los desafíos que se han identificado en distintas investigaciones (Coscarelli, 2009; Argüello, 2012; Pérez y Rincón, 2013; Cassany, 2013), entre los que se encuentran la dificultad para evaluar las fuentes de información, el uso de fuentes secundarias que reemplazan a las fuentes primarias, la superficialidad en el abordaje de ciertos textos, el uso de la información y los límites entre las actividades de ocio y las académicas. Estos desafíos pueden convertirse en potencialidades si se asumen orientaciones que ayuden a los estudiantes a enfrentarse adecuadamente a las distintas demandas, sin sacrificar sus posibilidades de aprender, de construir, transformar y de comunicar el conocimiento. 
Por tanto, el acompañamiento a los estudiantes en los procesos de lectura digital, y también en papel, es una realidad urgente de abordar en las instituciones. Esto lleva a una redefinición de los roles de docentes y funcionarios que trabajan en el acompañamiento a estas prácticas. Por ejemplo, el docente de lengua puede orientar sobre aspectos generales de comprensión de lectura y de criticidad, pero necesita el apoyo de los docentes de las distintas disciplinas para guiar a los estudiantes a través del currículo en la apropiación de los modos específicos de leer en sus áreas del conocimiento. Los funcionarios de las bibliotecas, como indica Cassany (2013), pueden ayudar a los alumnos a reconocer sus necesidades de información, a manejar los recursos para la búsqueda de fuentes, a evaluar la calidad de sus resultados, a citar y referenciar con rigurosidad las fuentes que usan.

Muchas de estas orientaciones no tienen que circunscribirse exclusivamente a la lectura digital, pues en la actualidad convergen distintos soportes y las prácticas de los estudiantes son híbridas, lo que enriquece y complejiza mucho más la labor de orientación.

\section{REFERENCIAS BIBLIOGRÁFICAS}

Albarello, F. (2011). Leer/navegar en internet: Las nuevas formas de lectura en la computadora. Buenos Aires: La Crujía Ediciones.

Argüello, L. (2012). Migraciones digitales de lectura y escritura en estudiantes universitarios. RUSC: Universities and Knowledge Society Journal, 9 (1), 5-21.

Barbero, J. (2008). Estallido de los relatos y pluralización de las lecturas. Comunicar. Revista Científica de Comunicación y Educación, xv (30), 15-20.

Bardin, L. (1996). Análisis de contenido. Madrid: Ediciones Akal S.A.

Bazerman, C.; Little, J.; Bethel, 1.; Chavkin, T.; Touquette, D. y Garufis, J. (2005). Reference Guide to Writing Across the Curriculum. West Lafayette, Indiana: Parlor Press.

Carlino, P. (2003). Alfabetización Académica: un cambio necesario, algunas alternativas posibles. Revista Educere, 6 (20), 409-420.

Carlino, P. (2005). Escribir, leer y aprender en la universidad: una introducción a la alfabetización académica. Buenos Aires: Fondo de Cultura Económica.

Carlino, P. (2013). Alfabetización académica diez años después. Revista Mexicana de Investigación Educativa, 18 (57), 355-381.

Cassany, D. (2009). Leer para Sophia. Tokio: Instituto Europeo de la Universidad de Sophia. Serie Cultura Hispánica, 17.

Cassany, D. (2013). En línea: Leer y escribir en la red. España: Anagrama.

Cavallo, G. y Chartier, R. (1997). Historia de la lectura en el mundo occidental. Madrid: Taurus.

Chartier, R. (1996). Del códice a la pantalla: trayectorias de lo escrito. Revista Quimera, (150), 43-49.

Cisneros, M.; Olave, G. y Rojas, I. (2012). Cómo mejorar la capacidad inferencial en estudiantes universitarios. Educación y Educadores, 75 (1), 45-61.

Coscarelli, C. (2009). Textos e Hipertextos: Procurando o Equilíbrio. Linguagem em (Dis) curso, Palboça, 9 (3), 549-564.

Cunliffe, D. (2000). Trailblazing: Trends in Hypermedia. The New Review of Hypermedia and Multimedia, 6, 19-46. 
Díaz, J. (2009). Multimedia y modalidades de lectura: una aproximación al estado de la cuestión. Comunicar. Revista Científica de Comunicación y Educación, XVII (33), 213-219.

Dillon, A. (1994). Designing Usable Electronic Text. Ergonomic Aspects of Human Information Usage. London: Taylor and Francis.

Dussel, I. (2009). Los nuevos alfabetismos en el siglo xxI. Desafíos para la escuela. Conferencia en Virtual Educa. Recuperado el 30 de marzo, 2015. http://www.virtualeduca. info/Documentos/veBA09\%20_confDussel.pdf.

Figueroa, B.; Ajagan, L.; Domínguez, L.; Yánez, V. y Aillon, M. (2007). Percepciones de los estudiantes de educación básica respecto de sus prácticas de lectura y escritura con apoyo del hipertexto. Theoria, 16 (2), 91-101.

Galindo, M. (2014). Hipertexto y criticidad. Desarrollo de las competencias digital y media a través del cine (tesis doctoral). Universidad Nacional de Educación a Distancia UNED. Facultad de Educación. España.

Gee, J. (1990). Social linguistics and literacies: Ideologies in discourses. London: Falmer.

Jenkins, H. (2008). Convergence culture: La cultura de la convergencia de los medios de comunicación. Barcelona: Paidós.

Kress, G. (2005). El alfabetismo en la era de los nuevos medios de comunicación. Granada: Ediciones El Aljibe.

Kruse, P. (2010). The Network Is Challenging Us. We-magazine. Recuperado el 5 de abril, 2015. http://www.we-magazine.net/we-volume-03/the-network-is-challenging-us/\#. VYMIYvmqqko.

Landow, G. (1995). Hipertexto. La convergencia de la teoría crítica contemporánea y la tecnología. Barcelona: Paidós-Hipermedia.

Lea, M. (2004). Academic literacies: a pedagogy for course design. Studies in Higher Education, 29 (6).

Levratto, V. (2014). Arquilectura. Modalidades de lectura en la web (tesis doctoral). Universidad Nacional de Educación a Distancia UNED. Facultad de Educación. España.

McEneaney, J. E. (2000). Navigational correlates of comprehension in hypertext. En K. Anderson y F. Shipman (Eds.). Proceedings of the 11th Hypertext Conference of the Association for Computing Machinery (pp. 254-255). New York: ACM Press.

McMillan, J. y Schumacher, S. (2005). Investigación educativa. 5. ${ }^{a}$ ed. Madrid: Pearson.

Morales, O. y Espinoza, N. (2013). Lectura y escritura: coexistencia entre lo impreso y lo electrónico. Educere, 7 (22), 213-222.

Morduchowicz, R. (2013). Los adolescentes de siglo XXI: los consumos culturales en un mundo de pantallas. México: Fondo de Cultura Económica.

Nelson, T. (1965). A File Structure for the complex, the changing and the indeterminate. En Proceedings of the ACM 20th National Conference (pp. 84-100). New York: ACM Press.

Nielsen, J. (1995). Multimedia and Hypertext: The Internet and Beyond. Boston: AP Professional.

Noorhidawati, A. y Gibb, F. (2008). How Students Use E-books-Reading or Referring? Malaysian Journal of Library \& Information Science, 13 (2), 1-14.

OCDE (2011). Resultados del informe PISA 2009: Estudiantes en Internet. Tecnologías y rendimientos digitales, vol. vI. España: Santillana.

Olmo, M. (2008). Nativo digital, lector multitarea. Notas sobre jóvenes, universidad y lectura en EE.UU. Educación y Biblioteca, (165), 130-140.

Perelman, F. et al. (2008). La tensión entre tener éxito y comprender en la búsqueda de información en Internet. Anuario de Investigaciones, xv, 135-144. 
Perelman, F. et al. (2009). Textos en pantalla y lecturas provisorias. Anuario de Investigaciones, XVI, 175-188.

Pérez, M. y Rincón, G. (Coords.) (2013). ¿Para qué se lee y se escribe en la universidad colombiana? Un aporte a la consolidación de la cultura académica del país. Bogotá: Editorial Pontificia Universidad Javeriana.

Piscitelli, A. (2011). El paréntesis de Gutenberg: la religión digital en la era de las pantallas ubicuas. Buenos Aires: Santillana.

Prensky, M. (2001). Digital Natives, Digital Immigrants. On the Horizon, MCB University Press, 9 (5), 1-6. Retrieved March 18, 2015: http://www.marcprensky.com/writing/ Prensky\%20-\%20Digital\%20Natives,\%20Digital\%20Immigrants\%20-\%20Part1.pdf.

Scolari, C. (2004). Hacer clic: Hacia una sociosemiótica de las interacciones digitales. Barcelona: Gedisa.

\section{ANEXO}

\section{CUESTIONARIO SOBRE LA PERCEPCIÓN DEL ESPACIO}

Esta encuesta tiene como propósito identificar las prácticas de lectura académica en pantallas de un grupo de estudiantes universitarios. Por favor, responde esta encuesta con la mayor sinceridad posible. Como se indicó en el consentimiento informado, las respuestas no tienen ninguna implicación en tu calificación del curso, pero sí aportan a la construcción de conocimiento sobre este tema. La participación es voluntaria y no implica ningún riesgo físico, afectivo o social; puedes retirarte cuando lo consideres conveniente y tus datos no serán incluidos. La información será usada únicamente con propósitos investigativos y se mantendrá el anonimato.

\section{A) DATOS GENERALES}

Nombre: Edad:

Carrera: Semestre:

Sexo: Estrato:

\section{B) Dispositivos Y CONECTIVIDAD}

1. ¿Con cuál/cuáles de los siguientes dispositivos cuentas para tu uso personal? (Puedes marcar varias respuestas)

\begin{tabular}{|l|l|}
\hline a) Computador de escritorio & \\
\hline b) Computador portátil & \\
\hline c) Tablet/Ipad & \\
\hline d) Smartphone & \\
\hline e) E-reader & \\
\hline f) Otro, ¿cuál? & \\
\hline g) Ninguno & \\
\hline
\end{tabular}


2. Indica la frecuencia ${ }^{3}$ con la que usas, de manera general, cada dispositivo (Marca una respuesta por cada dispositivo)

\begin{tabular}{|l|l|l|l|l|l|}
\hline \multicolumn{1}{|c|}{ Dispositivo } & $\begin{array}{c}\text { Muy } \\
\text { frecuente }\end{array}$ & Frecuente & $\begin{array}{c}\text { Poco } \\
\text { frecuente }\end{array}$ & Casi nunca & $\begin{array}{c}\text { No tienes o } \\
\text { no lo usas }\end{array}$ \\
\hline $\begin{array}{l}\text { a) } \\
\text { Computador de } \\
\text { escritorio }\end{array}$ & & & & & \\
\hline b) Computador portátil & & & & & \\
\hline c) Tablet/Ipad & & & & & \\
\hline d) Smartphone & & & & & \\
\hline e) E-reader & & & & & \\
\hline f) Otro, & & & & & \\
\hline
\end{tabular}

3. ¿Con qué servicios de conexión a Internet cuentas en tus dispositivos? (Puedes marcar varias respuestas)

\begin{tabular}{|l|l|}
\hline a) Conexión por cable & \\
\hline b) Conexión inalámbrica (Wi-Fi) privada & \\
\hline c) Conexión inalámbrica (Wi-Fi) pública & \\
\hline d) Plan de datos de Internet (personal) & \\
\hline e) Internet móvil (módem) & \\
\hline f) Otro, ¿cuál? & \\
\hline
\end{tabular}

4. ¿Lees en alguno de estos dispositivos? Sí No

5. En caso de marcar Sí en la pregunta anterior, ¿en cuál o cuáles? (Ordena según la frecuencia de uso)
a)
b)
c)
d)
e)
f)
g)

3. Muy frecuente significa que lo usas al menos una vez al día. Frecuente, al menos una vez a la semana. Poco frecuente: una vez al mes. Casi nunca: una vez por semestre. 
6. ¿Qué tipo de lectura realizas en línea y con qué frecuencia? (Puedes marcar varias respuestas)

\begin{tabular}{|c|c|c|c|c|c|}
\hline Tipo de lectura & A diario & Semanalmente & $\begin{array}{l}\text { Una vez } \\
\text { al mes }\end{array}$ & $\begin{array}{c}\text { Pocas } \\
\text { veces al } \\
\text { año }\end{array}$ & $\begin{array}{c}\text { ¿En qué } \\
\text { dispositivo? } \\
\text { (Puedes } \\
\text { marcar varias } \\
\text { respuestas) }\end{array}$ \\
\hline \multirow{6}{*}{$\begin{array}{l}\text { a) Informativa (con el } \\
\text { propósito de conocer lo } \\
\text { que pasa en el contexto } \\
\text { local, nacional o inter- } \\
\text { nacional, por ejemplo: } \\
\text { noticias, artículos de } \\
\text { opinión, textos } \\
\text { periodísticos en general) }\end{array}$} & & & & & Computador \\
\hline & & & & & Portátil___ \\
\hline & & & & & Tablet/Ipad__ \\
\hline & & & & & Smartphone__ \\
\hline & & & & & E-reader___ \\
\hline & & & & & Otro___ \\
\hline \multirow{6}{*}{$\begin{array}{l}\text { b) Académica (con el } \\
\text { objetivo de aprender y } \\
\text { realizar las actividades } \\
\text { de la universidad: capí- } \\
\text { tulos de libros, libros, } \\
\text { artículos científicos, } \\
\text { manuales, páginas web, } \\
\text { etc.) }\end{array}$} & & & & & Computador \\
\hline & & & & & Portátil___ \\
\hline & & & & & Tablet/Ipad \\
\hline & & & & & Smartphone \\
\hline & & & & & E-reader___ \\
\hline & & & & & Otro___ \\
\hline \multirow{6}{*}{$\begin{array}{l}\text { c) Social-recreativa (con } \\
\text { el propósito de entre- } \\
\text { tenerse, por ejemplo: } \\
\text { redes sociales, páginas } \\
\text { web...) }\end{array}$} & & & & & Computador \\
\hline & & & & & Portátil___ \\
\hline & & & & & Tablet/Ipad__ \\
\hline & & & & & Smartphone__ \\
\hline & & & & & E-reader \\
\hline & & & & & Otro___ \\
\hline \multirow{6}{*}{$\begin{array}{l}\text { d) Literaria (con el pro- } \\
\text { pósito de disfrutar de la } \\
\text { estética de la escritura, } \\
\text { por ejemplo: novelas, } \\
\text { cuentos, poemas, etc.) }\end{array}$} & & & & & Computador \\
\hline & & & & & Portátil ___ \\
\hline & & & & & Tablet/Ipad__ \\
\hline & & & & & Smartphone _ \\
\hline & & & & & E-reader \\
\hline & & & & & Otro \\
\hline d) Otra, ¿cuál? & & & & & \\
\hline
\end{tabular}

\section{C) PRÁcticas de leCtura en Pantallas}

Por favor, responde las siguientes preguntas teniendo en cuenta las lecturas que haces para tus actividades de aprendizaje en la universidad (en asignaturas, grupos de investigación, grupos de estudio, etc.). 
7. Generalmente, ¿en qué soporte lees para responder a las tareas de la universidad? (Marca una sola respuesta)

\begin{tabular}{|c|c|}
\hline a) & Papel \\
\hline & Pantalla \\
\hline & Ambos \\
\hline
\end{tabular}

8. ¿Qué soporte prefieres? (Marca una sola respuesta)

\begin{tabular}{|ll|l|}
\hline a) & Papel & \\
\hline b) & Pantalla & \\
\hline c) & Cualquiera de los dos & \\
\hline
\end{tabular}

9. ¿Qué lees normalmente en pantalla? (Puedes marcar varias respuestas)

\begin{tabular}{|c|c|}
\hline a) & Capítulos de libros \\
\hline b) & Artículos científicos \\
\hline c) & Páginas web \\
\hline d) & Blogs \\
\hline e) & Libros \\
\hline f) & Wikis \\
\hline g) & Resúmenes de libros o artículos \\
\hline h) & Trabajos de otros estudiantes \\
\hline i) & Manuales \\
\hline j) & Documentos periodísticos (noticias, crónicas, etc.) \\
\hline k) & Diapositivas \\
\hline 1) & Videos \\
\hline m) & Otro, ¿cuál? \\
\hline n) & Ninguno \\
\hline
\end{tabular}

10. En la universidad, cuál es el promedio de textos académicos (capítulo de libros o manuales, artículos) que lees por mes (Marca una sola opción)

\begin{tabular}{|l|l|}
\hline a) Ninguno & \\
\hline b) Menos de 3 & \\
\hline c) Entre 3 y 5 & \\
\hline d) Más de 5 & \\
\hline
\end{tabular}

11. De los textos asignados, ¿¿cuáles están en formato digital? (Marca una sola respuesta)

\begin{tabular}{|l|l|}
\hline a) Ninguno & \\
\hline b) Menos de la mitad & \\
\hline c) Aproximadamente la mitad & \\
\hline d) Más de la mitad & \\
\hline e) Todos & \\
\hline
\end{tabular}


12. Los textos que lees en pantalla, generalmente... (Puedes marcar varias respuestas)

\begin{tabular}{|l|l|}
\hline a) Son asignados o recomendados por el profesor & \\
\hline b) Son elegidos por ti, pero solicitados por el profesor & \\
\hline c) Son elegidos por ti, por tu propia iniciativa & \\
\hline d) Otro, ¿cuál? & \\
\hline
\end{tabular}

13. ¿Para qué actividades o con qué propósito lees en pantalla? (Puedes marcar varias respuestas)

\begin{tabular}{|c|c|c|}
\hline a) & Preparar un tema para una clase & \\
\hline b) & Responder a preguntas planteadas por el profesor & \\
\hline c) & Ampliar los contenidos vistos en una clase & \\
\hline d) & Escribir un texto académico (resumen, reseña, ensayo) & \\
\hline e) & $\begin{array}{l}\text { Elaborar organizadores gráficos (esquemas, mapas } \\
\text { conceptuales...) }\end{array}$ & \\
\hline f) & Estudiar para un examen parcial & \\
\hline g) & Entender un tema complejo & \\
\hline h) & Otro, ¿cuál? & \\
\hline
\end{tabular}

14. ¿Por qué lees en pantalla? (Puedes marcar varias respuestas)

\begin{tabular}{|l|l|}
\hline a) Es de fácil y rápido acceso & \\
\hline b) Permite hacer múltiples tareas al tiempo & \\
\hline c) Es más fácil de entender & \\
\hline d) Otro, ¿cuál? & \\
\hline
\end{tabular}

15. Cuando debes buscar información, generalmente... (Puedes marcar varias respuestas)

\begin{tabular}{|c|c|}
\hline a) & $\begin{array}{l}\text { Consultas las primeras fuentes que te ofrecen buscadores como } \\
\text { Google }\end{array}$ \\
\hline b) & $\begin{array}{l}\text { Consultas en buscadores como Google, pero tienes unos criterios } \\
\text { para evaluar las fuentes }\end{array}$ \\
\hline c) & Buscas y utilizas revistas electrónicas \\
\hline d) & Investigas en bases de datos electrónicas \\
\hline e) & No tienes un procedimiento específico para la búsqueda \\
\hline f) & Otra \\
\hline
\end{tabular}

16. Estrategias de lectura en pantalla

16.1. ¿Qué haces cuando lees en pantalla? (Puedes marcar varias respuestas)

\begin{tabular}{|c|c|}
\hline a) & Exploras de manera general la información \\
\hline b) & Lees solo partes del texto \\
\hline c) & Lees en profundidad el texto completo \\
\hline d) & Relees el texto \\
\hline
\end{tabular}




\begin{tabular}{|c|c|}
\hline e) & Exploras los hipervínculos que tiene el texto \\
\hline f) & Consultas otras fuentes para complementar la información \\
\hline g) & Otro, ¿cuál? \\
\hline h) & Ninguna \\
\hline
\end{tabular}

16.2. ¿Consideras que tus estrategias de lectura en pantallas son efectivas? (Marca una sola respuesta) Sí__ No

17. ¿Qué haces con la información que lees en pantalla? (Puedes marcar varias respuestas)

\begin{tabular}{|c|c|}
\hline a) & $\begin{array}{l}\text { Guardas los datos de la fuente para poderla referenciar en caso } \\
\text { de que uses la información }\end{array}$ \\
\hline b) & $\begin{array}{l}\text { Tomas nota de la información más relevante en otro archivo (un } \\
\text { documento en Word, por ejemplo) }\end{array}$ \\
\hline c) & $\begin{array}{l}\text { Elaboras un organizador gráfico (mapas, esquemas) con las ideas } \\
\text { principales }\end{array}$ \\
\hline d) & Resaltas las ideas principales en el texto \\
\hline e) & Comparas la información encontrada con otras fuentes \\
\hline f) & Identificas los puntos de vista de distintos autores y los contrastas \\
\hline g) & Evalúas críticamente la información encontrada \\
\hline h) & $\begin{array}{l}\text { Obtienes conclusiones que integran la información encontrada y } \\
\text { tus propias apreciaciones }\end{array}$ \\
\hline i) & Otro, ¿¿cuál? \\
\hline j) & Ninguna \\
\hline
\end{tabular}

18. Cuando lees en pantalla, ¿qué dificultades encuentras? (Puedes marcar varias respuestas)

\begin{tabular}{|c|c|}
\hline a) & Problemas para encontrar la información que requieres \\
\hline b) & $\begin{array}{l}\text { Problemas para evaluar la confiabilidad y validez de la } \\
\text { información }\end{array}$ \\
\hline c) & Dificultades para usar correctamente la información \\
\hline d) & $\begin{array}{l}\text { Dificultades para asumir una postura crítica y personal frente a la } \\
\text { información encontrada }\end{array}$ \\
\hline e) & Dificultades para comprender la información \\
\hline f) & Mientras lees te distraes haciendo otras actividades \\
\hline g) & Cansancio o fatiga física \\
\hline h) & Otro, ¿¿cuál? \\
\hline i) & Ninguna \\
\hline
\end{tabular}

19. ¿Mientras lees en pantalla, sueles llevar a cabo otras actividades? (Marca una sola respuesta) Sí__ No 
20. En caso de marcar Sí, ¿por qué realizas otras actividades mientras lees en pantalla?

21. ¿Cuáles de las siguientes actividades realizas al mismo tiempo que lees en pantalla? (Marca una de las dos opciones [SÍ o NO] en cada elemento)

\begin{tabular}{|l|c|c|}
\hline \multicolumn{1}{|c|}{ Actividades } & Sí & No \\
\hline a) Ver videos relacionados con el tema & & \\
\hline b) Ver videos no relacionados con el tema & & \\
\hline c) Consultar otros textos relacionados con el tema & & \\
\hline d) Escuchar música & & \\
\hline e) Chatear & & \\
\hline f) Revisar las redes sociales & & \\
\hline g) Leer otro texto académico & & \\
\hline h) Hacer otro trabajo de la universidad & & \\
\hline i) Explorar otros temas en Internet & & \\
\hline j) Jugar & & \\
\hline k) Otra, ¿cuál? & & \\
\hline
\end{tabular}

22. ¿En qué situaciones realizas esas actividades mientras lees en pantalla? (Marca una de las dos opciones [SÍ o NO] en cada elemento)

\begin{tabular}{|c|c|c|c|}
\hline \multicolumn{2}{|r|}{ Situaciones } & Sí & No \\
\hline & $\begin{array}{l}\text { Siempre que lees un texto académico en pantalla (así sea } \\
\text { un texto difícil de entender o así la tarea sea compleja de } \\
\text { realizar) }\end{array}$ & & \\
\hline b) & $\begin{array}{l}\text { Cuando el texto es sencillo y no requiere de mucha } \\
\text { concentración }\end{array}$ & & \\
\hline c) & Cuando el texto no te interesa o no te llama la atención & & \\
\hline d) & Otro, ¿cuál? & & \\
\hline
\end{tabular}

23. Cuando lees en papel, ¿también realizas otras actividades al tiempo? (Marca una sola respuesta)

Sí__ No

¿Por qué?

24. Consideras que hacer otras actividades mientras lees textos académicos... (Marca una de las dos opciones [SÍ o NO] en cada elemento)

\begin{tabular}{|ll|l|l|}
\hline & Sí & No \\
\hline a) Afecta negativamente tu nivel de comprensión de lectura & & \\
\hline b) Implica demorarte más en la realización de sus actividades & & \\
\hline c) No interfiere en la adecuada realización de la lectura & & \\
\hline d) Otra, ¿̇cuál? & & \\
\hline
\end{tabular}

25. En la universidad, ¿quién orienta tus procesos de lectura en pantalla? (Puedes marcar varias respuestas) 


\begin{tabular}{|l|l|}
\hline a) Los profesores de las distintas materias de tu carrera & \\
\hline b) Los profesores de lenguaje & \\
\hline c) La biblioteca & \\
\hline d) Recibes poca o ninguna orientación & \\
\hline e) Otro, ¿cuál? & \\
\hline
\end{tabular}

26. ¿Qué apoyos recibes en tus procesos de lectura en pantalla? (Puedes marcar varias respuestas)

\begin{tabular}{|c|c|}
\hline a) & $\begin{array}{l}\text { Tienes un módulo o unidad en una o varias materias de tu } \\
\text { carrera }\end{array}$ \\
\hline b) & $\begin{array}{l}\text { Tienes un módulo o unidad en una materia de lectura y de } \\
\text { escritura }\end{array}$ \\
\hline c) & $\begin{array}{l}\text { Cuando tienes una lectura, tus profesores te dan una guía } \\
\text { escrita con las orientaciones sobre cómo hacerlo en pantalla }\end{array}$ \\
\hline d) & $\begin{array}{l}\text { Cuando tienes una lectura en pantalla, tus profesores te dan } \\
\text { orientaciones de forma oral }\end{array}$ \\
\hline e) & $\begin{array}{l}\text { Algún profesor o funcionario te muestra (modela) cómo leer en } \\
\text { pantalla }\end{array}$ \\
\hline f) & $\begin{array}{l}\text { En la universidad cuentas con recursos en línea que te orientan } \\
\text { sobre cómo leer en pantalla }\end{array}$ \\
\hline g) & $\begin{array}{l}\text { En la universidad cuentas con recursos impresos que te orientan } \\
\text { sobre cómo leer en pantalla }\end{array}$ \\
\hline h) & Se realizan asesorías al respecto \\
\hline i) & Algún profesor o funcionario resuelve tus dudas al respecto \\
\hline j) & Otro, ¿¿cuál? \\
\hline k) & Ninguno \\
\hline
\end{tabular}

27. ¿Te gustaría o consideras importante recibir orientación sobre cómo leer en pantalla? (Marca una sola respuesta)

Sí_ No

28. ¿Sobre qué aspectos consideras pertinente recibir orientación? (Puedes marcar varias respuestas)

\begin{tabular}{|c|c|}
\hline a) & $\begin{array}{l}\text { Búsqueda de información en la Red (motores de búsqueda, } \\
\text { acceso a bases de datos electrónicas) }\end{array}$ \\
\hline b) & Evaluación de la confiabilidad y pertinencia de las fuentes \\
\hline c) & Estrategias de lectura específicas para los textos digitales \\
\hline d) & $\begin{array}{l}\text { Estrategias para interpretar otras modalidades de presentación } \\
\text { de información (gráficos, audio, video) }\end{array}$ \\
\hline e) & $\begin{array}{l}\text { Derechos de autor y uso adecuado de la información (evitar el } \\
\text { plagio) }\end{array}$ \\
\hline f) & Evitar o controlar las distracciones \\
\hline
\end{tabular}




\begin{tabular}{|ll|l|}
\hline g) & $\begin{array}{l}\text { Optimizar el uso de textos digitales (acudir a hipervínculos, } \\
\text { consultar otros textos, participar en comunidades de } \\
\text { aprendizaje) }\end{array}$ & \\
\hline h) & Contrastar y evaluar información para asumir una postura crítica & \\
\hline i) & Otros, ¿cuál? & \\
\hline j) & No consideras pertinente recibir orientación & \\
\hline
\end{tabular}

29. ¿A través de qué estrategias consideras que sería más adecuado o te gustaría recibir orientación? (Puedes marcar varias respuestas)

\begin{tabular}{|c|c|}
\hline a) & $\begin{array}{l}\text { Trabajar en un módulo sobre lectura en pantallas en una o } \\
\text { varias materias de tu carrera }\end{array}$ \\
\hline b) & $\begin{array}{l}\text { Trabajar en un módulo sobre lectura en pantallas en una } \\
\text { materia de lectura y de escritura }\end{array}$ \\
\hline c) & Trabajar en un módulo o curso presencial de la biblioteca \\
\hline d) & Trabajar en un módulo o curso virtual de la biblioteca \\
\hline e) & $\begin{array}{l}\text { Recibir orientaciones por parte de tus profesores, a través de } \\
\text { una guía escrita, cada vez que tienes actividades de lectura en } \\
\text { pantallas }\end{array}$ \\
\hline f) & Recibir asesorías de profesores \\
\hline g) & Trabajar en las tutorías del Centro de Escritura \\
\hline h) & Ver videos tutoriales que permitan el autoaprendizaje \\
\hline i) & $\begin{array}{l}\text { Acudir a recursos textuales impresos o en línea (folletos, } \\
\text { manuales) }\end{array}$ \\
\hline j) & Otros, ¿¿cuál___ _ _ _ \\
\hline k) & Ninguno \\
\hline
\end{tabular}

30. ¿Consideras que tu competencia para leer en pantallas es? (Marca una respuesta por cada elemento)

\begin{tabular}{|l|l|l|l|l|l|}
\hline & Excelente & Buena & Regular & Deficiente & Pésima \\
\hline $\begin{array}{l}\text { Competencia de lectura } \\
\text { (de forma global) }\end{array}$ & & & & & \\
\hline Búsqueda de información & & & & & \\
\hline Confiabilidad de las fuentes & & & & & \\
\hline $\begin{array}{l}\text { Uso adecuado de la } \\
\text { información }\end{array}$ & & & & & \\
\hline $\begin{array}{l}\text { Comprensión de diversos } \\
\text { géneros textuales y } \\
\text { modalidades }\end{array}$ & & & & & \\
\hline Lectura crítica & & & & & \\
\hline
\end{tabular}

